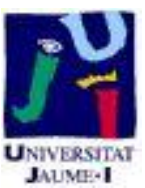

Título artículo / Títol article: Characterization of halloysite-water nanofluid for heat transfer applications

Autores / Autors

J. A. Alberola Borràs, R. Mondragón Cazorla, J. E. Juliá Bolívar, L. Hernández López, L. Cabedo Mas

Revista:

Applied Clay Science, v. 99 (Sept. 2014)

Versión / Versió:

Postprint de l'autor

Cita bibliográfica / Cita bibliogràfica (ISO 690):
ALBEROLA BORRÀS, J. A.; MONDRAGÓN CAZORLA, R.; JULIÁ BOLÍVAR. J. E.; HERNÁNDEZ LÓPEZ, L.; CABEDO MAS, L. Characterization of halloysite-water nanofluid for heat transfer applications. Applied Clay Science, v. 99 (Sept. 2014), pp. 54-61

url Repositori UJI: http://repositori.uji.es/xmlui/handle/10234/122703 
Research Paper

\title{
Characterization of halloysite-water nanofluid for heat transfer applications
}

\author{
J.A. Alberola ${ }^{\text {a }}$, R. Mondragón ${ }^{\text {b }}$, J.E. Juliá ${ }^{\text {b }}$, L. Hernández ${ }^{\text {b }}$, L. Cabedo a,* \\ a Polymers and Advanced Materials Group (PIMA), Universitat Jaume I, Campus de Riu Sec, 12071 Castellón de la Plana, Spain \\ b Departamento de Ingeniería Mecánica y Construcción, Universitat Jaume I, Campus de Riu Sec, 12071 Castellón de la Plana, Spain
}

\section{A R T I C L E I N F O}

\section{Article history:}

Received 3 February 2014

Received in revised form 9 June 2014

Accepted 11 June 2014

Available online $\mathrm{xxxx}$

\section{Keywords:}

Nanofluid

Halloysite

Thermal conductivity

Viscosity

Specific heat

\begin{abstract}
A B S T R A C T
Nanofluids based on water with halloysite (Hal) nanotubes were prepared and characterized in order to evaluate its suitability to be used as a heat transfer fluid. A characterization of the Hal powder nanoparticles was performed by means of SEM, TEM, WAXS, FTIR and TGA so that chemical composition, size and shape were determined. Stability of nanofluids was analyzed by means of zeta potential and light transmission measurements. Thermal conductivity, specific heat and viscosity of nanofluids prepared at different solid contents $(0.5,1,3$ and $5 \%$ volume fraction) and temperatures $\left(40,60\right.$ and $80{ }^{\circ} \mathrm{C}$ ) were obtained in order to optimize the Prandtl number. The nanofluids exhibited a good performance for its application as heat transfer fluids, with low Prandtl numbers compared to other commonly used nanofluids. High thermal conductivity enhancement with moderate viscosity and good stability results was obtained for the Hal nanofluid.
\end{abstract}

(c) 2014 Elsevier B.V. All rights reserved.

\section{Introduction}

A technological approach to reduce energy consumption is to enhance performance of heat exchange systems. Heat transfer plays an important role in many fields such as power generation, chemical processes, air conditioning, transportation, microelectronics and any application in which heating and cooling processes are involved. The enhanced efficiency would allow reducing the size of the devices and decrease the operating costs of associated processes (Fan and Wang, 2011; Godson et al., 2010; Özerinç et al., 2010).

One of the parameters limiting the performance of heat exchange systems is the inherent low thermal conductivity of conventional heat transfer fluids. In the last years intensive research efforts have increased to solve this problem. As possible alternative could be the addition of solid particles with thermal conductivity higher than that of the fluid. In 19th century, Maxwell first dispersed small particles into a base fluid (Maxwell, 1873). Further works demonstrated that the addition of micrometer- or millimeter-sized particles enhances heat transfer properties but it causes sedimentation of large particles, clogging of flow channels, erosion of pipelines and pressure drops. This problem can be solved by adding nanoparticles (colloidal particles with main size smaller than $100 \mathrm{~nm}$ ) into the base fluid. High specific surface of nanoparticles, high dispersion stability, reduced particle clogging and adjustable properties make nanofluids an interesting solution to

\footnotetext{
* Corresponding author. Tel.: + 34964728193.

E-mail address: lcabedo@uji.es (L. Cabedo).
}

enhance the performance of heat exchange systems (Buongiorno et al., 2009; Li et al., 2009; Özerinç et al., 2010; Saidur et al., 2011).

Due to advances in nanotechnology, Masuda et al. (1993) first dispersed alumina $\left(\mathrm{Al}_{2} \mathrm{O}_{3}\right)$ ultrafine particles (13 nm in the mean diameter) in water, increasing thermal conductivity by $30 \%$. Choi (1995) proposed the concept of nanofluid (dilute dispersions with solid particles smaller than $100 \mathrm{~nm}$ ) to enhance thermal conductivity. Lee et al. (1999) dispersed alumina and copper oxide (CuO) nanoparticles in water and ethylene glycol (EG). These authors found that thermal conductivity increased linearly with the volume fraction. Nanofluid attention grew when Eastman et al. (2001) reported their results in nanofluids with copper $(\mathrm{Cu})$ nanoparticles and EG as base fluid. They found a substantial enhancement of thermal conductivity. The same year Choi et al. (2001) dispersed multiwall carbon nanotubes (MWCNT) in water measuring an enhancement up to $160 \%$ at only $1 \%$ volume fraction of MWCNT. From this moment, there have been many studies in three kinds of nanoparticles dispersed in heat transfer fluids, namely metallic particles as aluminum (Al) (Murshed et al., 2008) and gold (Au) (Putnam et al., 2006), CNT (Biercuk et al., 2002; Segarra et al., 2013; Xie et al., 2003), and non-metallic particles as silica $\left(\mathrm{SiO}_{2}\right)$, alumina $\left(\mathrm{Al}_{2} \mathrm{O}_{3}\right)$ (Mondragon et al., 2013) and titania $\left(\mathrm{TiO}_{2}\right)$ (Murshed et al., 2005). The convective heat transfer coefficient has been also studied (Juliá et al., 2012; Kim et al., 2009a,b).

However, different results and trends were found for the same materials characterized by different researchers, depending mainly in the procedure followed to prepare the nanofluids and the final state of agglomeration of the solid particles. In order to compare the values of thermal conductivity obtained by different researchers, a benchmark 
study was carried out (Buongiorno et al., 2009). The same samples of $\mathrm{Al}_{2} \mathrm{O}_{3}, \mathrm{SiO}_{2}$, Au and $\mathrm{Mn}-\mathrm{Zn}$ ferrite nanofluids were analyzed by several laboratories, at room temperature (ranging from 20 to $30^{\circ} \mathrm{C}$ ), using the different available techniques, so the results could be compared and experimental error could be determined.

The lack of agreement between experimental results and theory has inspired efforts in identifying responsible heat transfer mechanisms (Fan and Wang, 2011): (1) liquid-layering, (2) aggregation, (3) particle motion, and (4) others. The second mechanism stimulates phonons transference along large particles or particle aggregates, which involves that particles with large aspect ratio have better heat transfer properties (Fan and Wang, 2011; Ghosh et al., 2013; Özerinç et al., 2010). As a result, the size and shape of nanoparticles and clusters formed are the key factors for the thermal conductivity enhancement (Gao et al., 2009; Prasher et al., 2006; Shima et al., 2010; Warrier et al., 2010; Wu et al., 2010). It was demonstrated that chain-like structures and nanotubes or nanofibers provide the highest thermal conductivity. Because of this, researches have focused on the use of carbon nanotubes to enhance thermal properties of fluids (Ding et al., 2006; Garg et al., 2009; Kim et al., 2009a,b; Talaei et al., 2011).

Although the addition of nanoparticles improves the thermal properties and heat transfer capabilities of fluids, the industrial applicability of nanofluids in heat transfer systems is limited by the increase of the viscosity of the fluid (which increases the pumping power). However, as also occurred with the conductivity measurement, the viscosity of nanofluids is highly dependent on the degree of agglomeration of the particles so that very different results can be obtained depending on the particle size and shape, being the chain-like structures those presenting the highest viscosities. Therefore, the use of carbon nanotubes is limited by its high viscosity. Hence, the combined study of thermal properties (thermal conductivity and specific heat) and rheological properties (viscosity) is of great importance, although only few works include rheological measurements of nanofluids (Lee et al., 2008; Pastoriza-Gallego et al., 2009, 2011; Yu et al., 2012). As it was done for thermal conductivity, a benchmark study was carried out (Venerus et al., 2010), in order to compare the values of viscosity obtained by different researchers, when the same samples of $\mathrm{Al}_{2} \mathrm{O}_{3}, \mathrm{SiO}_{2}$, and $\mathrm{Mn}-\mathrm{Zn}$ ferrite nanofluids were analyzed by several laboratories, at room temperature (ranging from 20 to $26^{\circ} \mathrm{C}$ ).

One of the challenges in thermal applications is to find a nanofluid providing the best thermal conductivity to viscosity ratio thus increasing the efficiency of heat transfer processes. Recently, thanks to its structure and properties, halloysite (Hal) nanotubes have increased their interest for the nanotechnology of advanced materials in areas such as catalysis, drug delivery, biomedical implants, corrosion protection of metals, biosensors, organic synthesis, flame retardant coatings, specific ion adsorbents, materials for sustained release of herbicides and antimicrobials and energy storage devices (Deen et al., 2012). Hal is a clay mineral of the kaolin group, having a hollow tubular-like structure with particle sizes within the nanometrical size range and large aspect ratio. The outer diameter of typical Hal nanotubes is within the range of 15-100 nm, and length is between 500 and $1500 \mathrm{~nm}$ (Alhuthali and Low, 2013; Cavallaro et al., 2012; Lvov et al., 2008; Pasbakhsh et al., 2013; Vergaro et al., 2010). The size and shape of Hal nanotubes together with its chemical composition and structure make this material a good candidate to be dispersed in water, thus obtaining an interesting nanofluid for heat transfer applications. Other interesting applications of Hal nanotubes are as carriers for drug delivery, adsorbents and fillers in clay polymer nanocomposites (Tan et al., in press)

In the present work, the suitability of using Hal nanotubes-water nanofluids as heat transfer fluids is studied. To the best of our knowledge this is the first work using Hal as a nanoparticle for obtaining a nanofluid to be used in heat transfer applications. The solid powder was first characterized by means of SEM, TEM, WAXS, FTIR and TGA. Then nanofluids at different nanoparticle volume fractions (from 0.5 to $5 \%$ ) were prepared and their thermal conductivity, specific heat and viscosity were measured at different temperatures $\left(40,60\right.$ and $\left.80^{\circ} \mathrm{C}\right)$. In order to evaluate the suitability of this as a good heat transfer nanofluid the Prandtl number (Pr) was obtained. Prandtl number $\left(\operatorname{Pr}=\eta_{\mathrm{nf}} \cdot C_{\mathrm{p}, \mathrm{nf}} / k_{\mathrm{nf}}\right)$ compares thermal properties like specific heat $\left(C_{\mathrm{p}, \mathrm{nf}}\right)$ and thermal conductivity $\left(k_{\mathrm{nf}}\right)$, with viscosity $\left(\eta_{\mathrm{nf}}\right)$. Experimental results showed that Hal nanotubes-water nanofluids present good characteristics to be considered as heat transfer fluids: high conductivity and moderate viscosity. Moreover, nanofluids were checked to remain stable for at least $24 \mathrm{~h}$.

\section{Materials and methods}

\subsection{Materials}

Tests were carried out with Hal nanotubes. Chemical formula of Hal is $\mathrm{Al}_{2} \mathrm{Si}_{2} \mathrm{O}_{5}(\mathrm{OH})_{4} \cdot \mathrm{nH}_{2} \mathrm{O}$, where $n=0-2$. Anhydrous form of Hal $(n=0)$ has a basal spacing of $0.7 \mathrm{~nm}$, while hydrated form $(n=2)$ has a basal spacing of $1 \mathrm{~nm}$ (Deen et al., 2012; Lvov et al., 2008; Rozynek et al., 2013). Outer surface of Hal nanotubes consists of tetrahedral siloxane groups ( $\mathrm{Si}-\mathrm{O}-\mathrm{Si})$, whereas inner consists of aluminol groups $(\mathrm{Al}-\mathrm{OH})$ (Alhuthali and Low, 2013; Kadi et al., 2012). Neighborhood of aluminol and siloxane layers provides a highly disordered structure with random dislocations and shifts, which rolls up the multilayer forming the hollow tubular form (Vergaro et al., 2010; Alhuthali and Low, 2013; Rozynek et al., 2013).

The powder used in this work was supplied by the U.S. company "NaturalNano, Inc." According to the manufacturer, Hal nanotube composition is between 98 and $99.8 \%$ of Hal. Hal nanotubes are ultra-tiny hollow tubes with diameters typically smaller than $100 \mathrm{~nm}$, with lengths typically ranging from about $500 \mathrm{~nm}$ to over $1.2 \mu \mathrm{m}$.

Nanofluids with different volume concentrations $(0.5,1,3$ and 5\%) were prepared by adding distilled water to the defined amounts of nanoparticles. In this method, known as the two-step method, the nanoparticles are purchased in dry powder and then dispersed in the liquid medium. The dispersion was made using an ultrasonic probe (HD2200 Sonopuls, Bandelin) and the mixture was submitted to a sonication treatment for $2 \mathrm{~min}$. Afterwards, the $\mathrm{pH}$ of the nanofluid was modified by adding $\mathrm{HCl}$ or $\mathrm{NaOH}$ solutions ( $10 \%$ mass) in order to modify the surface charges of the particles and to electrostatically stabilize the dispersion. Finally, to ensure a correct dispersion of all the components, the nanofluids were submitted to a second sonication treatment during 2 min.

\subsection{Experimental methods}

Scanning electron microscopy (SEM) was performed in a Leica-Zeiss LEO 440 microscope equipped with digital image acquisition. Powder samples were observed so the morphology and size of the raw material were determined.

Transmission electron microscopy (TEM) images were obtained using a JEOL 2100 microscope at an operating voltage of $100 \mathrm{kV}$. TEM was used to observe the morphology and size of Hal nanotubes and clusters in the dispersion. In order to do this, a small amount of the sample was dropped on a copper grid and then was dried to remove the liquid. To prevent large agglomeration of particles during the drying of the sample very diluted nanofluids were prepared.

Wide angle X-ray scattering experiments (WAXS) were performed using a Bruker AXS D4 Endeavor diffractometer. Radial scans of intensity versus scattering angle $(2 \theta)$ were recorded at room temperature in the range $2-30^{\circ} 2 \theta$ (step size $=0.02^{\circ} 2 \theta$, scanning rate $=8 \mathrm{~s} / \mathrm{step}$ ) with identical setting of the instrument by using filtered CuKa radiation $(\lambda=1.54 \AA$ ), an operating voltage of $40 \mathrm{kV}$, and a filament current of $30 \mathrm{~mA}$. To calculate the clay mineral $d$-value, Bragg's law $(\lambda=2 \mathrm{~d}$ $\sin \theta$ ) was applied.

Fourier transform infrared (FTIR) spectra were collected for the Hal powder using a Jasco FT/IR-6200 spectrometer in attenuated total 
reflection (ATR) mode. The FTIR-ATR instrument was operated in the wavenumber range of $600-4000 \mathrm{~cm}^{-1}$, with a diamond/ZnSe crystal, 32 scans and resolution of $4 \mathrm{~cm}^{-1}$. A background scan of clean diamond/ZnSe crystal was acquired before scanning the samples.

Thermogravimetric (TGA) tests were carried out using a TG-STDA Mettler Toledo thermogravimetric analyzer. Samples of approximately $15-20 \mathrm{mg}$ were scanned from 50 up to $900{ }^{\circ} \mathrm{C}$ at $10 \mathrm{~K} / \mathrm{min}$. All scans were performed with a flow of $50 \mathrm{~cm}^{3} / \mathrm{min}$ of nitrogen.

The zeta potential $(\psi)$ was measured using a Zetasizer Nano ZS (Malvern Instruments Ltd., UK) from the electrophoretic mobility of particles when an electric field is applied. This velocity was measured using laser Doppler velocimetry (LDV) and the zeta potential was obtained through the Henry equation.

The particle size distributions $\left(d_{\mathrm{p}}\right)$ were determined by dynamic light scattering (DLS) using a Zetasizer Nano ZS (Malvern Instruments Ltd., UK). Particle size was measured from the velocity of the particles due to their Brownian motion by means of the Einstein-Stokes equation.

The thermal conductivity $(k)$ of all nanofluids was measured using a KD2 Pro conductimeter (Decagon Devices Inc.). The KD2 Pro is the commercial device that measures the thermal conductivity with the help of the transient hot wire technique. In this method, a thin metallic wire is embedded in the test liquid acting as both heat source and temperature sensor. The transient hot wire technique works by measuring the temperature/time response of the wire to an abrupt electrical pulse. The thermal conductivity of the test sample can be derived from the temperature change of the hot wire over a specific time interval. The sample was introduced in a sealed glass tube $(20 \mathrm{ml})$ where the sensor was inserted vertically. To carry out the test at high temperature conditions the tube was submerged in a thermostatic bath where the temperature was controlled. A period of time of $1 \mathrm{~h}$ was waited for the sample to reach the desired temperature before any test. After that time, six measurements were done for each nanofluid sample. Within the measurement time the bath was switched off to avoid vibrations. It was important to wait for about 15 min between readings to recover the temperature reached after the heat pulse applied to the nanofluid.

The KD2 Pro uses special algorithms to analyze measurements made during a heating and a cooling interval. The device was specially design to measure the thermal conductivity of solids or liquids at low temperatures where the temperature is not affected by external changes. However, in this case the sample was introduced in a bath, and when the bath was switched off to avoid vibrations, the decrease of the bath temperature during the reading time influenced the evolution of the fluid temperature when the heat pulse was applied. Therefore, the internal equations of the KD2 Pro and the values registered by it could not be used to fit the data, as those influences and contributions were not taken into account. Experimental data for the evolution of the temperature due to the heat pulse were fitted to the following equation:

$T=m_{0}+m_{1} t+m_{2} \ln t$

where $m_{0}$ is the ambient temperature during heating, $m_{1}$ is the rate of background temperature drift and $m_{2}$ is the slope of a line relating temperature rise to logarithm of time. The thermal conductivity can be computed from the parameter $m_{2}$ :

$k_{\mathrm{nf}}={\frac{q}{4 \pi m_{2}}}^{k=\frac{q}{4 \pi m_{3}}}$

where $k_{\mathrm{nf}}$ is the thermal conductivity and $q$ is the power of the heat pulse applied.

Differential scanning calorimetry (DSC) measurements were carried out to determine the specific heat $\left(C_{\mathrm{p}}\right)$ for each nanofluid using DSC1 instrument (Mettler Toledo, USA). The sequence used in the specific heat determination was as follows: isotherm of $5 \mathrm{~min}$ at $25{ }^{\circ} \mathrm{C}$, dynamic segment from 25 to $85{ }^{\circ} \mathrm{C}$ at a heating rate of $10{ }^{\circ} \mathrm{C} / \mathrm{min}$ and isotherm of
5 min at $85{ }^{\circ} \mathrm{C}$. As a consequence of the nature of the sample (liquid), the crucible (aluminum) was sealed in order to avoid loss of material by evaporation. Previous to the sample tests, a blank measurement was run with an empty cell following the same treatment in order to counterbalance the measuring cell calorimetric response. Heat flow measurements were calibrated with indium and zinc calibration standards in the whole temperature range, thus providing a $5 \%$ error in the specific heat measurements.

The viscosity $(\eta)$ and rheological behavior of nanofluids were obtained by conducting tests under steady state conditions using a Haake RheoStress 1 rotational rheometer (Thermo Scientific). A system composed of two concentric cylinders was used. In the gap between the inner cylinder (diameter $=34 \mathrm{~mm}$ ) and the outer cylinder (diameter $=36.88 \mathrm{~mm}$ ) $40 \mathrm{ml}$ of sample was introduced. Before each test, a pre-treatment, in which the samples were submitted to a constant shear stress, was applied to the nanofluids for $30 \mathrm{~s}$ to ensure similar starting conditions for all the measurements.

The stability of the nanofluids was analyzed through the evolution of the amount of light backscattered by the nanofluid from an incident laser beam. Measurements were based on the multiple light scattering theory (Amiri et al., 2009; Mondragon et al., 2012). Stability in colloid science is used not only in the thermodynamic sense but also in a strictly colloidal sense. "Colloidally stable" means that the colloidal particles do not settle and do not agglomerate at a significant rate (Bergna and Roberts, 2006). The experimental device consists of a laser beam and a detector that measures the light transmitted by the sample. For each nanofluid, the transmission profiles were obtained at different heights along the cell. To analyze the stability of nanofluids the measurements were carried out at different time intervals up to a total time of $24 \mathrm{~h}$.

\section{Results and discussion}

\subsection{Halloysite characterization}

Hal nanotubes acquired in dry powder were characterized so that the morphology, size, internal structure, chemical composition and thermal stability were determined, previous to the production of nanofluids.

Figs. 1 and 2 report, respectively for SEM and TEM, images of the tubular morphology of Hal nanotubes. The platy particles observed in the SEM image can be attributed to residual kaolinite. Image treatment of the micrographs allowed determining the mean diameter and the mean length of the nanotubes, which have been found to be 0.09 and $1.31 \mu \mathrm{m}$, respectively, being thus the calculated aspect ratio of ca. 14.5. In the TEM micrograph (Fig. 2) the internal structure of the Hal is visible,

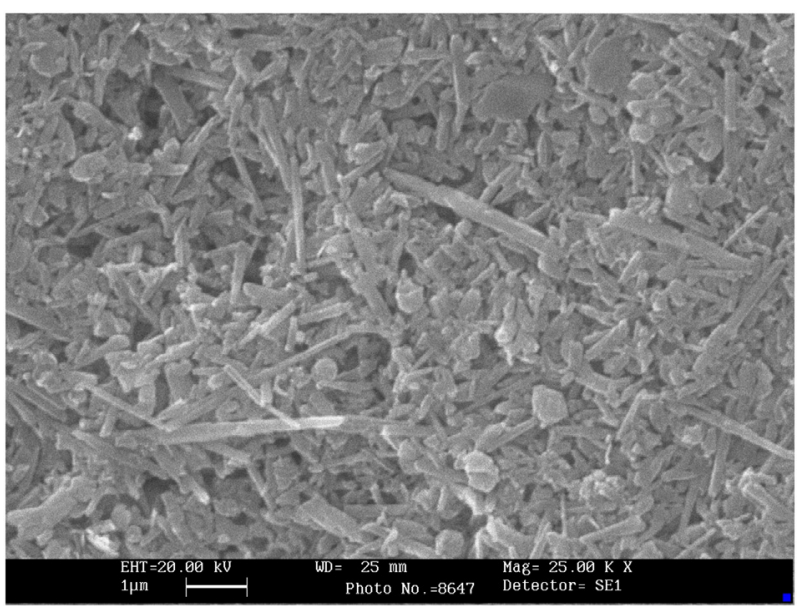

Fig. 1. SEM image of Hal nanotube powder 


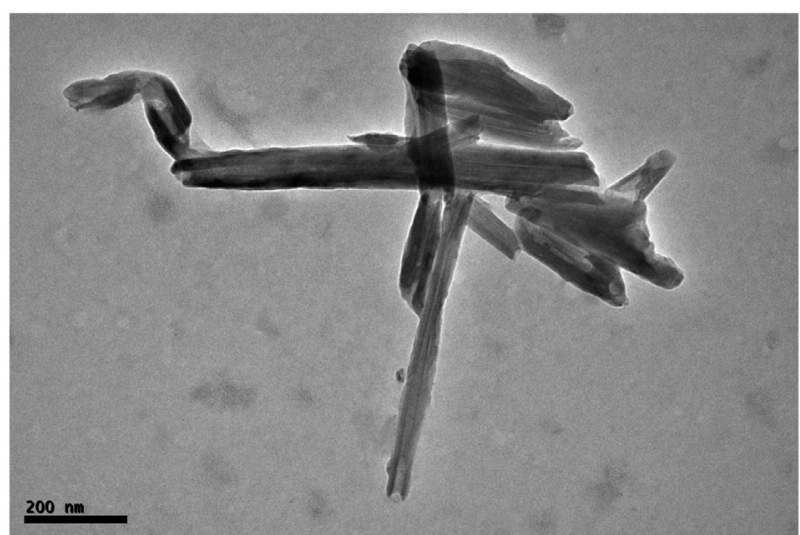

Fig. 2. TEM image of Hal nanotube powder.

i.e. the stacking of the clay mineral layers in a hollow tubular-like particle.

WAXS pattern of the Hal is represented Fig. 3. Three characteristic reflections at $2 \theta$ values of $11.95^{\circ}, 20.15^{\circ}$ and $24.95^{\circ}$ can be detected. The former corresponds to basal reflection of the clay mineral, which by applying the Bragg's law yields a $d$-value of $0.74 \mathrm{~nm}$. This result suggests that the Hal is in anhydrous form (Alhuthali and Low, 2013; Cheng et al., 2010; Kadi et al., 2012; Lvov et al., 2008; Rozynek et al., 2013; Zhang et al., 2012). The peak at $20.15^{\circ} 2 \theta$ can be ascribed to the 020 reflection, while the one at $24.95^{\circ} 2 \theta$ is the 002 . The lack of clear peaks in the range from the 020 reflection to 002 suggests a big structural disorder (Rozynek et al., 2013).

FTIR-ATR experiments of the Hal powder were also performed and the spectrum is plotted in Fig. 4. In it hydroxyl groups of aluminol present in the inner layer can be identified; specifically vibration at $3620 \mathrm{~cm}^{-1}$ can be assigned to the $\mathrm{O}-\mathrm{H}$ stretching of inner hydroxyl groups, while the band at $3696 \mathrm{~cm}^{-1}$ can be attributed to stretching of inner-surface hydroxyl groups (Cheng et al., 2010; Kadi et al., 2012; Yuan et al., 2012). Peak at $1593 \mathrm{~cm}^{-1}$ is attributed to bending vibrations of absorbed water (Cheng et al., 2010; Frost et al., 1998; Kadi et al., 2012). In the 1300 to $500 \mathrm{~cm}^{-1}$ range, the peak at $1117 \mathrm{~cm}^{-1}$ is assigned to stretching mode of apical $\mathrm{Si}-\mathrm{O}$ bonds, while the bands at 1030 and $907 \mathrm{~cm}^{-1}$ are caused by the stretching vibrations of $\mathrm{Si}-\mathrm{O}-\mathrm{Si}$ and bending modes of $\mathrm{Al}-\mathrm{O}-\mathrm{H}$. The bands at 796 and $7466 \mathrm{~cm}^{-1}$ correspond to $\mathrm{OH}$ translation vibrations of Hal (Cheng et al., 2010).

Thermal stability of Hal nanotubes measured by TGA is plotted in Fig. 5. Tests were carried out within the temperature range of 50-

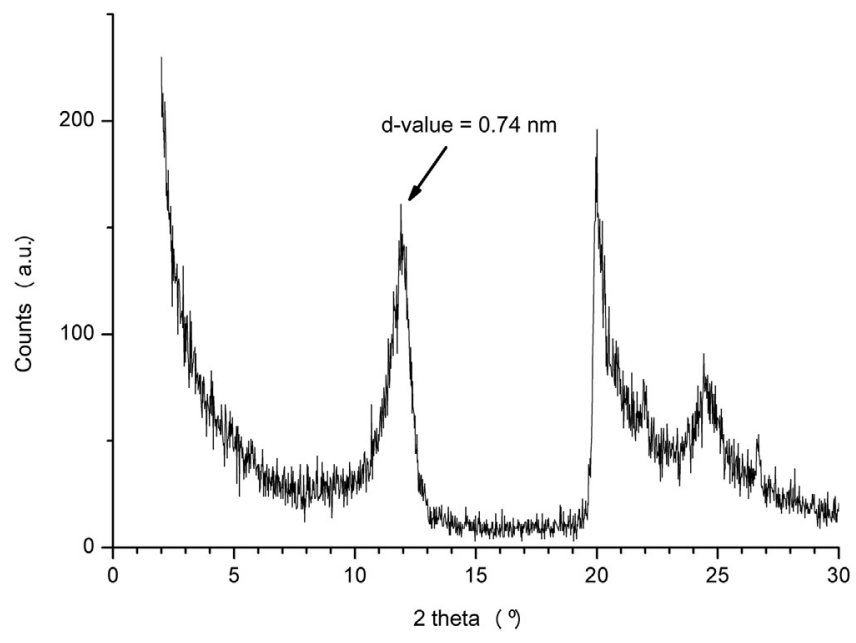

Fig. 3. Hal pattern measured by WAXS.

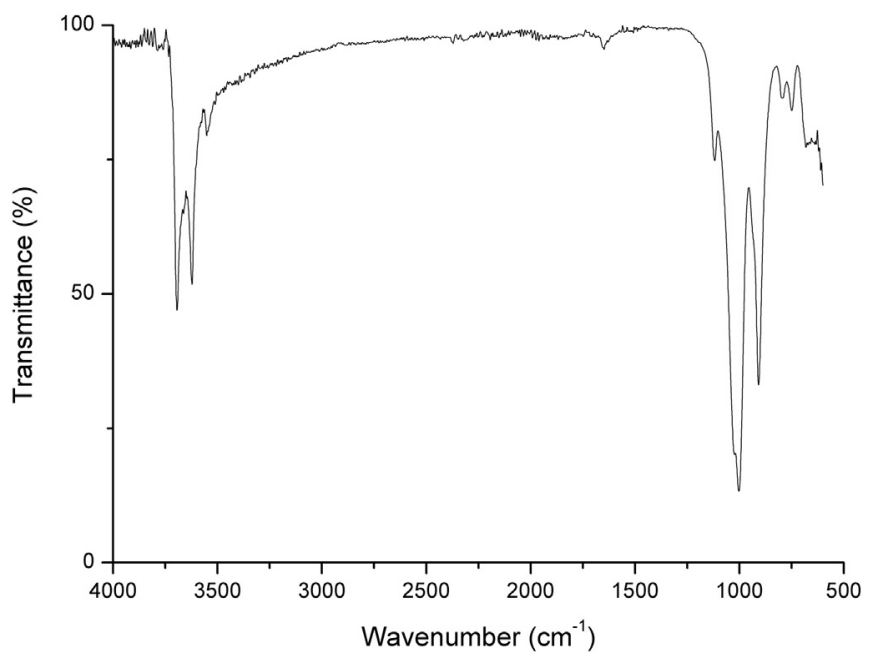

Fig. 4. Hal spectrum obtained by FTIR-ATR.

$900{ }^{\circ} \mathrm{C}$. Weak absorbed water to particle surface is easily removed at temperatures slightly above $60{ }^{\circ} \mathrm{C}$. Above $200{ }^{\circ} \mathrm{C}$ there is a little slope of mass loss due to the removing of water physisorbed at e.g. the micropores of clay (Frost and Vassallo, 1996; Kadi et al., 2012; Nicolini et al., 2009; Rozynek et al., 2013). The most important mass loss takes place at $490{ }^{\circ} \mathrm{C}$, due to the dehydroxylation of the aluminol layers in the Hal.

\subsection{Nanofluid characterization}

One of the main characteristics that make nanofluids of interest is their high stability. In order to prepare stable water based dispersions, nanoparticles have to be electrostatically stabilized by adjusting the $\mathrm{pH}$ value. For each system and chemical substance there is a $\mathrm{pH}$ value at which the surface charge in the shear plane that surrounds the particle takes a value of zero and particles agglomerate when get approach. This pH is known as isoelectric point (IEP) (Hunter, 1988). Consequently, to prepare well-stabilized dispersions, $\mathrm{pH}$ values far away from the IEP are needed.

To determine the IEP of the nanofluids, the zeta potential of dispersions prepared at $\mathrm{pH}$ values of 2, 4, 6, 8, 10 and 12 was measured. All the measurements were carried out in dilute dispersion at a $0.5 \%$ volume fraction. The $\mathrm{pH}$ value was modified by addition of $\mathrm{HCl}$ and $\mathrm{NaOH}$. Fig. 6 plots the Z-potential values obtained versus the $\mathrm{pH}$ value for each nanofluid prepared. According to these results, the nanofluid's Z-potential reaches a zero value at $\mathrm{pH}=3.5$ close to that of the silica

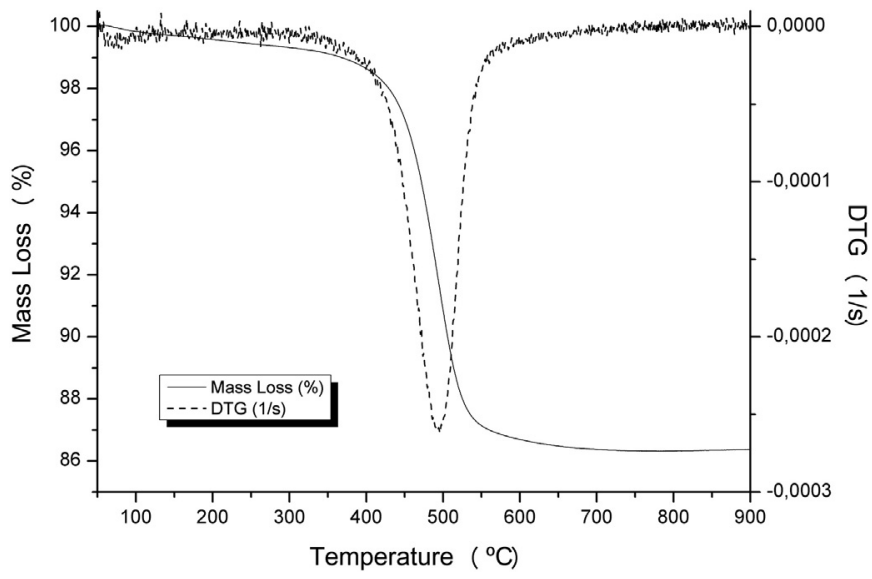

Fig. 5. TGA and DTG curves obtained for Hal. 


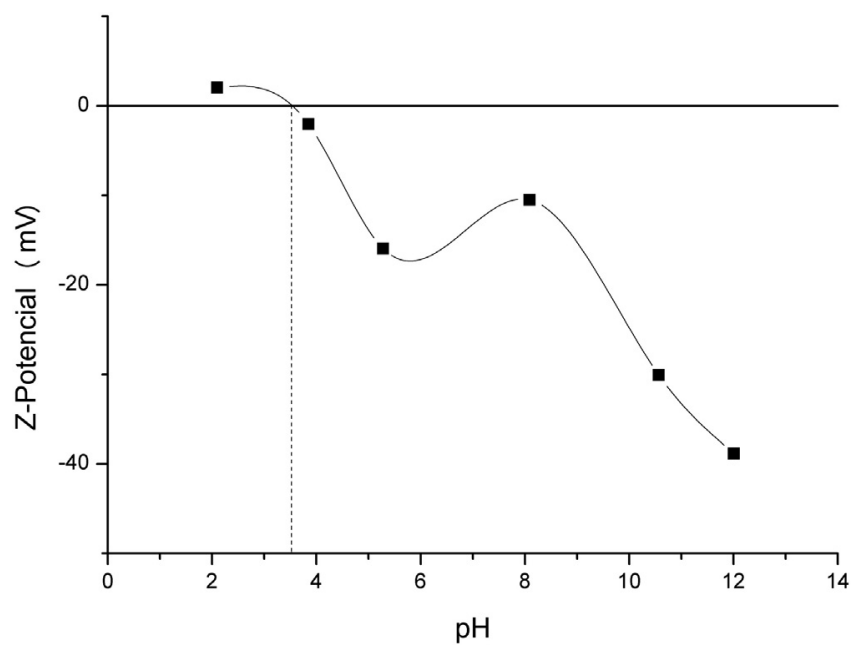

Fig. 6.Z-potential curve as a function of $\mathrm{pH}$ value for Hal nanofluid at $0.5 \%$ volume fraction.

$(\mathrm{IEP}=2)$. At $\mathrm{pH}=8$ there is a slight increase which can be attributed to the aluminol surface (which has an IEP of 9). The silica behavior is more pronounced than that of alumina because is located on outer surface (Deen et al., 2012; Zhang et al., 2012). Therefore, the IEP for Hal nanotubes is located at $\mathrm{pH}=3.5$ and the $\mathrm{pH}$ value at which the nanofluid reaches the highest stability is located at $\mathrm{pH}=12$ with a corresponding Z-potential value of about $-39 \mathrm{mV}$. The other tested nanofluids were also prepared at this $\mathrm{pH}$ value to ensure stability.

The stability of the nanofluid prepared at $0.5 \%$ volume fraction and $\mathrm{pH}=12$ was checked through the evolution with time of the amount of light transmitted by the sample at different sample heights. The ratio between the light backscattered at a certain time and the corresponding value at $t=0$ for different heights is plotted in Fig. 7. As it can be concluded from the measurements, the values do not change significantly either with time or with height, thus proving the stability of the dispersion. As a result, the stability of nanofluids at $\mathrm{pH}=12$ can be guaranteed for at least $24 \mathrm{~h}$.

Particle size distribution in number for the dispersion containing $0.5 \%$ volume fraction of Hal nanotubes was measured with DLS and is

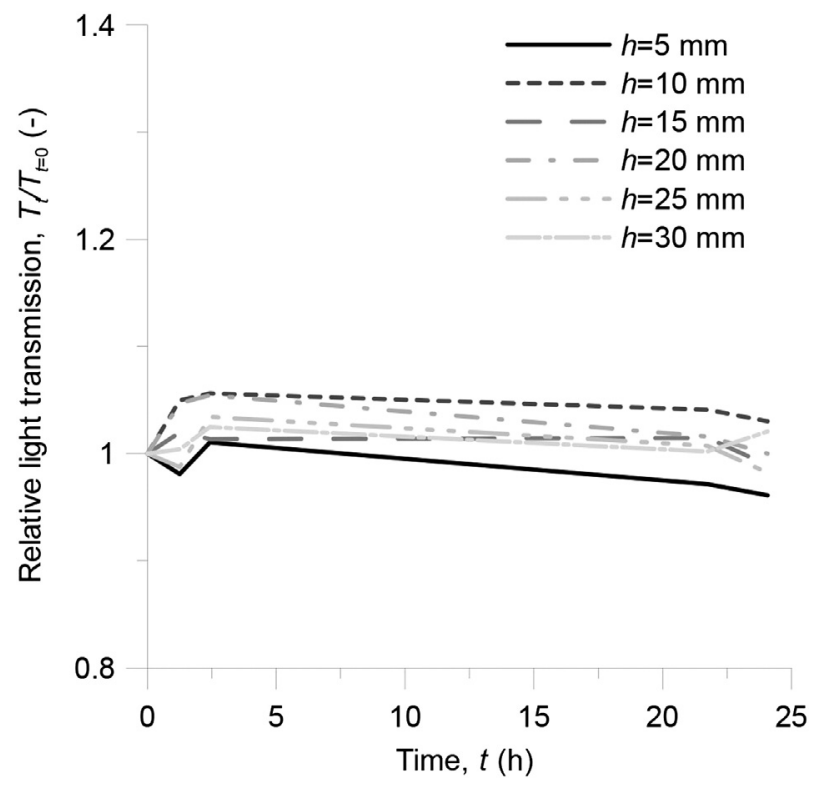

Fig. 7. Evolution with time of light transmission profiles of Hal nanofluid at $\mathrm{pH}=12$.

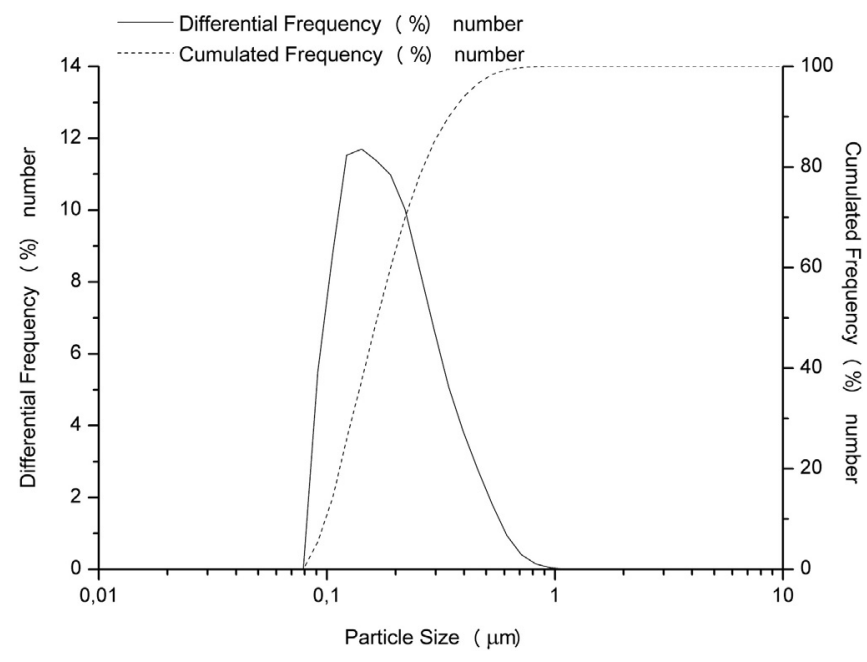

Fig. 8. Particle size distribution of Hal nanofluid at $0.5 \%$ volume fraction.

represented in Fig. 8. This plot exhibits a monomodal distribution and its shape is representative of all the studied nanofluids (volume fractions $0.5,1,3$ and $5 \%)$. The characteristic diameters $\left(d_{10}, d_{50}\right.$ and $\left.d_{90}\right)$, as obtained from the respective curves, can be found in Table 1 for the different volume fraction percentages. The dispersion containing $0.5 \%$ of Hal nanotubes exhibited a $d_{50}$ of $0.180 \mu \mathrm{m}$. This value is almost 10 times smaller than the average length of the nanotubes, as determined by SEM observation. However, the mean particle size is bigger than the nanotube diameter, being thus this $d_{50}$ value the size of an aggregated structure, i.e. a Hal nanotube cluster. This means that nanotubes dispersed in water are not perfectly dispersed but forming clusters. The mean size and size distribution width decrease when the solid content is increased, probably revealing a decrease in the average cluster diameter size.

\subsection{Thermophysical properties of nanofluids}

The evolution of the thermal conductivity, specific heat and viscosity of base fluid and Hal nanofluids at different solid content $(0.5,1,3$ and $5 \%$ volume fraction) and temperature $\left(40,60\right.$ and $\left.80{ }^{\circ} \mathrm{C}\right)$ was measured and studied.

The thermal conductivity enhancement $\left(k_{\mathrm{r}}\right)$ was calculated dividing nanofluid and base fluid thermal conductivities ( $k_{\mathrm{nf}}$ and $k_{\mathrm{bf}}$ respectively). The evolution of the thermal conductivity enhancement of all tested nanofluids, together with the bar error corresponding to the six experimental measurements for each condition, is plotted in Fig. 9a. Thermal conductivity increases with solid content due to the higher number of particles present in the dispersion and the higher number of contacts between them (Keblisnki et al., 2001). For very low solid contents, the degree of dispersion is higher and the addition of nanoparticles to the base fluid does not provide a significant increase in the thermal conductivity. To obtain an increase in the thermal conductivity related to the base fluid, solid contents higher than $1 \%$ are needed. The maximum thermal conductivity enhancement achieved at $5 \%$ volume fraction was of $8 \%$. As a general trend, thermal conductivity decreases with temperature, although significant differences were not found.

Table 1

Characteristic diameters of particle size distribution for different solid content.

\begin{tabular}{llll}
\hline Volume fraction $(\%)$ & $d_{10}(\mu \mathrm{m})$ & $d_{50}(\mu \mathrm{m})$ & $d_{90}(\mu \mathrm{m})$ \\
\hline 0.5 & 0.11 & 0.18 & 0.38 \\
1 & 0.06 & 0.08 & 0.2 \\
3 & 0.013 & 0.02 & 0.02 \\
5 & 0.011 & 0.02 & 0.02 \\
\hline
\end{tabular}



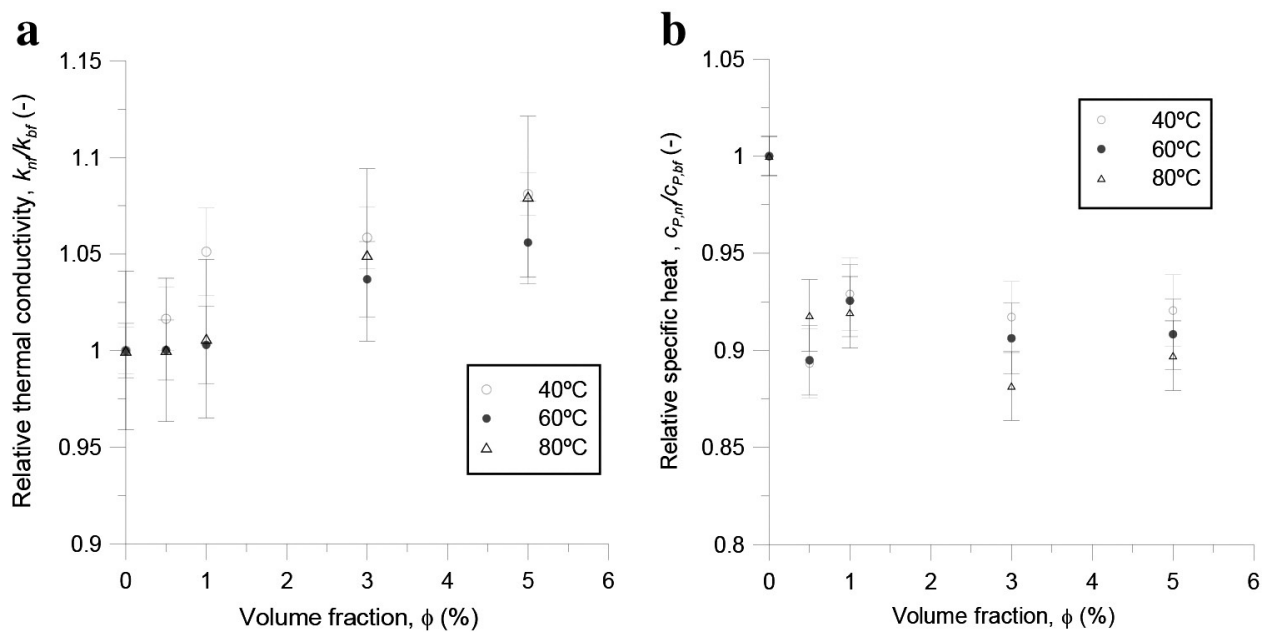

Fig. 9. Evolution of (a) relative thermal conductivity and (b) relative specific heat with volume fraction and temperature.

Specific heat capacity of all prepared nanofluids was experimentally measured at different solid content and temperature conditions. Evolution of the relative specific heat between nanofluid $\left(C_{\mathrm{p}, \mathrm{nf}}\right)$ and base fluid $\left(C_{\mathrm{p}, \mathrm{bf}}\right)$ with these two variables is presented in Fig. $9 \mathrm{~b}$. The specific heat describes the amount of heat required to increase the temperature of the sample by a given amount. As expected, the specific heat decreases with the addition of Hal, due to the lower specific heat of the solid phase with respect to that of the liquid phase. However, the evolution with solid content and temperature is negligible and differences can be attributed to the experimental error.

Fig. 10a shows the rheological behavior of nanofluids at $T=40^{\circ} \mathrm{C}$. Shear stress varies linearly with shear rate according to Newton's law and it can be concluded that nanofluids behave newtonian. When temperature is increased, viscosity decreases while keeping the same behavior (not shown in the figure). From these data, viscosity of nanofluids is obtained by means of the Newton's law. Fig. 10b shows the evolution of the relative viscosity of the nanofluids with solid content and temperature. Viscosity ratio was calculated from nanofluid and base fluid viscosities ( $\eta_{\mathrm{nf}}$ and $\eta_{\mathrm{bf}}$ respectively). The viscosity of the nanofluid increases with solid content according to the models available in literature (Quemada, 1977). As the solid content increases, there exists more interaction between particles so that clusters are formed providing a higher viscosity. Besides, the increment of viscosity is more important for high temperature conditions, meaning that the influence of temperature is different between nanofluids and base fluid. The nanofluid presenting the highest thermal conductivity enhancement is also the one with the highest viscosity (65\% enhancement over the base fluid).

In order to evaluate if Hal nanofluids are appropriate to be used as heat transfer fluids, providing a good thermal behavior with lowest penalty in viscosity (pumping power), Prandtl number $\left(P r=c_{\mathrm{P}} \cdot \eta / k\right)$ was calculated by using all physical properties measured at different experimental conditions. This dimensionless number represents the ratio between viscous and thermal forces. Low values of the Prandtl number indicate high thermal conductivity together with moderate viscosities. In Fig. 11a evolution of relative Prandtl number with solid content and temperature is shown for Hal nanofluids. Prandtl number increases with solid content as thermal conductivity and viscosity also present similar trends.

In Fig. 11b, relative Prandtl numbers of Hal nanotubes at $80{ }^{\circ} \mathrm{C}$ are compared to previous experimental results (Mondragon et al., 2013) for different nanofluids ( silica, alumina and carbon nanotubes). It can be concluded that Hal nanofluids present the lowest values of Prandtl number. These and the previous experimental results (Mondragon et al., 2013) indicate that viscosity is the most important variable for Prandtl number. Therefore, similar thermal conductivity enhancement could be achieved for Hal nanotubes but with lower viscosities than

Fig. 10. (a) Rheological behavior of nanofluids at $T=40^{\circ} \mathrm{C}$. (b) Evolution of relative viscosity with volume fraction and temperature. 

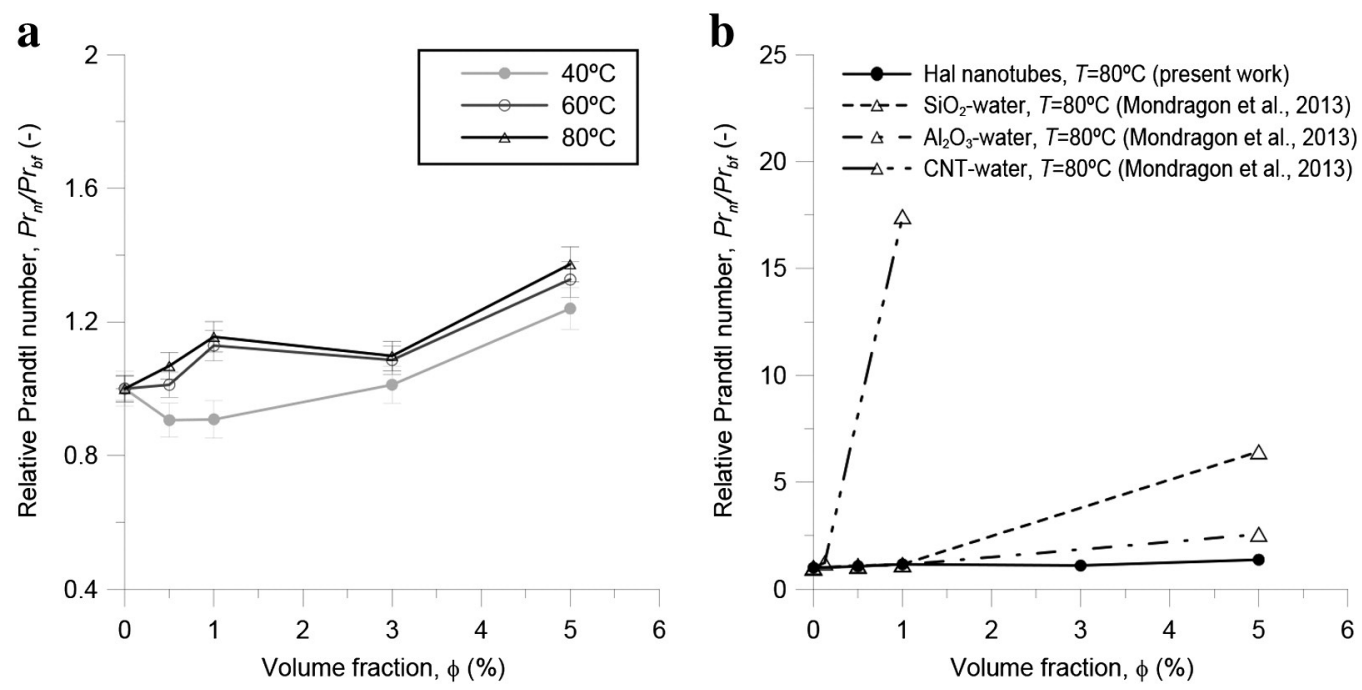

Fig. 11. Evolution of relative Prandtl number with volume fraction for (a) Hal nanotubes and (b) different nanofluids.

for metal oxides and carbon nanotubes. Hal nanotubes combine two positive characteristics: the tubular morphology leads to good thermal conductivity while the chemical composition leads to a better dispersion in water and low viscosity. As a result, Hal nanofluids can be considered to be used as heat transfer fluid.

\section{Conclusions}

In the present study Hal nanotubes were studied as a potential nanoparticle for obtaining water-based nanofluids for heat transfer applications. Initially the clay mineral was studied in powder form by means of SEM, TEM, WAXS, FTIR and TGA, revealing the results a high purity, a well-defined tubular shape and a large aspect ratio.

The stability of the nanofluid was proved by light transmission measurements. Particle size and particle size distribution of nanotubes in water were experimentally measured, revealing formation of clusters and a decrease in the cluster size with increasing solid contents.

Thermophysical properties were analyzed in order to evaluate the capability of Hal nanofluids to be used as heat transfer fluid, revealing an increase in thermal conductivity with solid content up to an $8 \%$ for the nanofluid at $5 \%$ of Hal nanotubes volume fraction and $T=80^{\circ} \mathrm{C}$. Viscosity also increased with solid content, while the specific heat of nanofluids decreased when nanoparticles were introduced. Finally, the Prandtl number was calculated, revealing that Hal nanofluids have a good thermal behavior and lower Prandtl numbers compared to other nanofluids. This could be explained due to the tubular morphology leading to a good thermal conductivity and the chemical composition leading to a better dispersion in water and low viscosity. In conclusion, Hal nanofluids can be considered to be used as heat transfer fluid.

\section{Acknowledgments}

The authors gratefully acknowledge the financial support from the Spanish Ministry of Science and Innovation (project CTQ2010-21321C02-02) and Universitat Jaume I (project P1-1B2013-43). The authors wish to thank Raquel Oliver, José Ortega and Salvador Torró for the experimental support.

\section{References}

Alhuthali, A., Low, I.M., 2013. Water absorption, mechanical, and thermal properties of halloysite nanotube reinforced vinyl-ester nanocomposites. J. Mater. Sci. 48, 4260-4273.

Amiri, A., Oye, G., Sjöblom, J., 2009. Influence of pH, high salinity and particle concentration on stability and rheological properties of aqueous suspensions of fumed silica. Colloids Surf. A Physicochem. Eng. Asp. 349, 43-54.
Bergna, H.E., Roberts, W.O., 2006. Colloidal Silica: Fundamentals and Applications. CRC Taylor \& Francis,

Biercuk, M.J., Llaguno, M.C., Radosavljevic, M., Hyun, J.K., Johnson, A.T., Fischer, J.E., 2002. Carbon nanotube composites for thermal management. Appl. Phys. Lett. 80, 2767-2769.

Buongiorno, J., et al., 2009. A benchmark study on the thermal conductivity of nanofluids. J. Appl. Phys. 106, 094312.

Cavallaro, G., Lazzara, G., Milioto, S., 2012. Exploiting the colloidal stability and solubilization ability of clay nanotubes/ionic surfactant hybrid nanomaterials. J. Phys. Chem. C 116, 21932-21938.

Cheng, H.F., Frost, R.L., Yang, J., Liu, Q.F., He, J.K., 2010. Infrared and infrared emission spectroscopic study of typical Chinese kaolinite and halloysite. Spectrochim. Acta A Mol. Biomol. Spectrosc. 77, 1014-1020.

Choi, S.U.S., 1995. Enhancing thermal conductivity of fluids with nanoparticles. ASME Int. Mech. Eng. Congress and Exp., San Francisco, CA, USA.

Choi, S.U.S., Zhang, Z.G., Yu, W., Lockwood, F.E., Grulke, E.A., 2001. Anomalous thermal conductivity enhancement in nanotube suspensions. Appl. Phys. Lett. 79, 2252-2254.

Deen, I., Pang, X., Zhitomirsky, I., 2012. Electrophoretic deposition of composite chitosanhalloysite nanotube-hydroxyapatite films. Colloids Surf. A Physicochem. Eng. Asp. $410,38-44$

Ding, Y., Alias, H., Wen, D., Williams, R., 2006. Heat transfer of aqueous suspensions of carbon nanotubes (CNT nanofluids). Int. J. Heat Mass Trans. 49, 240-250.

Eastman, J.A., Choi, S.U.S., Li, S., Yu, W., Thompson, L.J., 2001. Anomalously increased effective thermal conductivities of ethylene glycol-based nanofluids containing copper nanoparticles. Appl. Phys. Lett. 78, 718-720.

Fan, J., Wang, L.Q., 2011. Review of heat conduction in nanofluids. J. Heat Transfer Trans. ASME 133, 1-14.

Frost, R.L., Vassallo, A.M., 1996. The dehydroxylation of the kaolinite clay minerals using infrared emission spectroscopy. Clay Clay Miner. 44, 635-651.

Frost, R.L., Kristof, J., Paroz, G.N., Kloprogge, J.T., 1998. Role of water in the intercalation of kaolinite with hydrazine. J. Colloid Interf. Sci. 208, 216-225.

Gao, J.W., Zheng, R.T., Ohtani, H., Zhu, D.S., Chen, G., 2009. Experimental investigation of heat conduction mechanisms in nanofluids. Clue on clustering. Nano Lett. 9, 4128-4132.

Garg, P., Alvarado, J., Mord, C., 2009. An experimental study on the effect of ultrasonication on viscosity and heat transfer performance of multi-wall carbon nanotube-based aqueous nanofluids. Int. J. Heat Mass Trans. 52, 5090-5101.

Ghosh, M.M., Ghosh, S., Pabi, S.K., 2013. Effects of particle shape and fluid temperature on heat-transfer characteristics of nanofluids. J. Mater. Eng. Perform. 22, 1525-1529.

Godson, L., Raja, B., Lal, D.M., Wongwises, S., 2010. Enhancement of heat transfer using nanofluids-An overview. Renew. Sustain. Energy Rev. 14, 629-641.

Hunter, R.J., 1988. Zeta potential in colloid science. Principles and applicationsAcademic Press Limited,.

Juliá, J.E., Hernández, L., Martínez-Cuenca, R., Hibiki, T., Mondragón, R., Segarra, C., Jarque, J.C., 2012. Measurement and modelling of forced convective heat transfer coefficient and pressure drop of $\mathrm{Al}_{2} \mathrm{O}_{3}$ - and $\mathrm{SiO}_{2}$-water nanofluids. 6th European Thermal Sciences Conference, pp. 1-8.

Kadi, S., Lellou, S., Marouf-Khelifa, K., Schott, J., Gener-Batonneau, I., Khelifa, A., 2012. Preparation, characterisation and application of thermally treated Algerian halloysite. Microporous Mesoporous Mater. 158, 47-54.

Keblisnki, P., Phillpot, S.R., Choi, S.U.S., Eastman, J.A., 2001. Mechanisms of heat flow in suspensions of nano-sized particles (nanofluids). Int. J. Heat Mass Trans. 45, 855-863.

Kim, D., Kwon, Y., Cho, Y. Li, C. Cheong, S., Hwang, Y., Lee, J., Hong, D., Moon, S., 2009a. Convective heat transfer characteristics of nanofluids under laminar and turbulent flow conditions. Curr. Appl. Phys. 9, E119-E123.

Kim, N.-J., Park, S.-S., Lim, S.H., Chun, W., 2009b. A study on the characteristics of carbon nanofluids at the room temperature $\left(25^{\circ} \mathrm{C}\right)$. Int. Comm. Heat Mass Tran. 38 , 313-318.

Lee, S., Choi, S.U.S., Li, S., Eastman, J.A., 1999. Measuring thermal conductivity of fluids containing oxide nanoparticles. J. Heat Transfer Trans. ASME 121, 280-289. 
Lee, J.H., Hwang, K.S., Jang, S.P., Lee, B.H., Kim, J.H., Choi, S.U.S., Choi, C.J., 2008. Effective viscosities and thermal conductivities of aqueous nanofluids containing low volume concentrations of $\mathrm{Al}_{2} \mathrm{O}_{3}$ nanoparticles. Int. J. Heat Mass Tranfer 51, 2651-2656.

Li, Y.J., Zhou, J.E., Tung, S., Schneider, E., Xi, S.Q., 2009. A review on development of nanofluid preparation and characterization. Powder Technol. 196, 89-101.

Lvov, Y.M., Shchukin, D.G., Möhwald, H., Price, R.R., 2008. Halloysite clay nanotubes for controlled release of protective agents. ACS Nano 2, 814-820.

Masuda, H., Ebata, A., Teramae, K., Hishinuma, N., 1993. Alteration of thermal conductivity and viscosity of liquid by dispersing ultra-fine particles. Netsu Bussei 7, 227-233.

Maxwell, J., 1873. A treatise on electricity and magnetism. Oxford Univ. Press, London, p. 365.

Mondragon, R., Julia, J.E., Barba, A., Jarque, J.C., 2012. Characterization of silica-water nanofluids dispersed with an ultrasound probe: a study of their physical properties and stability. Powder Technol. 224, 138-146.

Mondragon, R., Segarra, C., Martinez-Cuenca, R., Julia, J.E., Jarque, J.C., 2013. Experimental characterization and modeling of thermophysical properties of nanofluids at high temperature conditions for heat transfer applications. Powder Technol. 249, 516-529.

Murshed, S.M.S., Leong, K.C., Yang, C., 2005. Enhanced thermal conductivity of $\mathrm{TiO}_{2}-$ water based nanofluids. Int. J. Therm. Sci. 44, 367-373.

Murshed, S.M.S., Leong, K.C., Yang, C., 2008. Investigations of thermal conductivity and viscosity of nanofluids. Int. J. Therm. Sci. 47, 560-568.

Nicolini, K.P., Fukamachi, C.R.B., Wypych, F., Mangrich, A.S., 2009. Dehydrated halloysite intercalated mechanochemically with urea: thermal behavior and structural aspects. J. Colloid Interf. Sci. 338, 474-479.

Özerinç, S., Kakac, S., Yazicioglu, A.G., 2010. Enhanced thermal conductivity of nanofluids: a state-of-the-art review. Microfluid. Nanofluid. 8, 145-170.

Pasbakhsh, P., Churchman, G.J., Keeling, J.L., 2013. Characterisation of properties of various halloysites relevant to their use as nanotubes and microfibre fillers. Appl. Clay Sci. 74, 47-57.

Pastoriza-Gallego, M. J., Casanova, C., Paramo, R., Barbes, B., Legido, J.L., Piñeiro, M.M., 2009 A study on stability and thermophysical properties (density and viscosity) of Al2O3 in water nanofluid. J. Appl. Phys. 106, 064301.

Pastoriza-Gallego, M.J., Lugo, L., Legido, J.L., Piñeiro, M.M., 2011. Themal conductivity and viscosity measurements of ethylene glycol-based $\mathrm{Al}_{2} \mathrm{O}_{3}$ nanofluids. Nanoscale Res. Lett. 6, 221.

Prasher, R., Phelan, P.E., Bhattacharya, P., 2006. Effect of aggregation kinetics on the thermal conductivity of nanoscale colloidal solutions (nanofluid). Nano Lett. 6, 1529-1534.

Putnam, S.A., Cahill, D.G., Braun, P.V., Ge, Z.B., Shimmin, R.G., 2006. Thermal conductivity of nanoparticle suspensions. J. Appl. Phys. 99, 084308
Quemada, D., 1977. Rheology of concentrated disperse systems and minimum energy dissipation principle. I. Viscosity-concentration relationship. Rheol. Acta 16, 82-94.

Rozynek, Z., Zacher, T., Janek, M., Čaplovičová, M., Fossum, J.O., 2013. Electric-field-induced structuring and rheological properties of kaolinite and halloysite. Appl. Clay Sci. 77-78, 1-9.

Saidur, R., Leong, K.Y., Mohammad, H.A., 2011. A review on applications and challenges of nanofluids. Renew. Sustain. Energy Rev. 15, 1646-1668.

Segarra, C., Jarque, J.C., Castello, J., Mondragon, R., Juliá, J.E., Hernández, L., MartínezCuenca, R., 2013. Characterization of Physical Properties of Nanofluids with Carbon Nanotubes for Heat Transfer Applications. 8th World Conference on Experimental Heat Transfer, Fluid Mechanics, and Thermodynamics, pp. 1-7.

Shima, P.D., Philip, J., Raj, B., 2010. Influence of aggregation on thermal conductivity in stable and unstable nanofluids. Appl. Phys. Lett. 97, 153113.

Talaei, Z., Reza, A., Rashidi, A., Amrollahi, A., Emami, M., 2011. The effect of functionalized group concentration on the stability and thermal conductivity of carbon nanotube fluid as heat transfer media. Int. Commun. Heat Mass Trans. 38, 513-517.

Tan, D.Y., et al., 2014. Loading and in vitro release of ibuprofen in tubular halloysite. Appl. Clay Sci. (In Press).

Venerus, D.C., et al., 2010. Viscosity measurements on colloidal dispersions (nanofluids) for heat transfer applications. Appl. Rheol. 20, 44582.

Vergaro, V., Abdullayev, E., Lvov, Y.M., Zeitoun, A., Cingolani, R., Rinaldi, R., Leporatti, S. 2010. Cytocompatibility and Uptake of Halloysite Clay Nanotubes. Biomacromolecules $11,820-826$

Warrier, P., Yuan, Y., Beck, M.P., Teja, A.S., 2010. Heat transfer in nanoparticle suspensions: modelling of thermal conductivity of nanofluids. AIChE J. 56, 3243-3256.

Wu, C., Cho, T.J., Xu, J., Lee, D., Yang, B., Zachariah, M.R., 2010. Effect of clustering on the effective thermal conductivity of concentrated silica colloids. Phys. Rev. E. 81, 011406

Xie, H.Q., Lee, H., Youn, W., Choi, M., 2003. Nanofluids containing multiwalled carbon nanotubes and their enhanced thermal conductivities. J. Appl. Phys. 94, 4967-4971.

Yu, W., Xie, H., Li, Y., Chen, L., Wang, Q., 2012. Experimental investigation on the heat transfer properties of $\mathrm{Al}_{2} \mathrm{O}_{3}$ nanofluids using the mixture of ethylene glycol and water as base fluid. Powder Technol. 230, 14-19.

Yuan, P., Tan, D., Annabi-Bergaya, F., Yan, W., Fan, M., Liu, D., He, H., 2012. Changes in structure, morphology, porosity, and surface activity of mesoporous halloysite nanotubes under heating. Clay Clay Miner. 60, 561-573.

Zhang, Y, Cao, H.M., Fei, W.W. Cui, D.X., Jia, N.Q, 2012. Direct electrochemistry and electrocatalysis of hemoglobin immobilized into halloysite nanotubes/room temperature ionic liquid composite film. Sensors Actuators B Chem. 162, 143-148. 
Research Paper

\title{
Characterization of halloysite-water nanofluid for heat transfer applications
}

\author{
J.A. Alberola ${ }^{\text {a }}$, R. Mondragón ${ }^{\text {b }}$, J.E. Juliá ${ }^{\text {b }}$, L. Hernández ${ }^{\text {b }}$, L. Cabedo a,* \\ a Polymers and Advanced Materials Group (PIMA), Universitat Jaume I, Campus de Riu Sec, 12071 Castellón de la Plana, Spain \\ b Departamento de Ingeniería Mecánica y Construcción, Universitat Jaume I, Campus de Riu Sec, 12071 Castellón de la Plana, Spain
}

\section{A R T I C L E I N F O}

\section{Article history:}

Received 3 February 2014

Received in revised form 9 June 2014

Accepted 11 June 2014

Available online $\mathrm{xxxx}$

\section{Keywords:}

Nanofluid

Halloysite

Thermal conductivity

Viscosity

Specific heat

\begin{abstract}
A B S T R A C T
Nanofluids based on water with halloysite (Hal) nanotubes were prepared and characterized in order to evaluate its suitability to be used as a heat transfer fluid. A characterization of the Hal powder nanoparticles was performed by means of SEM, TEM, WAXS, FTIR and TGA so that chemical composition, size and shape were determined. Stability of nanofluids was analyzed by means of zeta potential and light transmission measurements. Thermal conductivity, specific heat and viscosity of nanofluids prepared at different solid contents $(0.5,1,3$ and $5 \%$ volume fraction) and temperatures $\left(40,60\right.$ and $80{ }^{\circ} \mathrm{C}$ ) were obtained in order to optimize the Prandtl number. The nanofluids exhibited a good performance for its application as heat transfer fluids, with low Prandtl numbers compared to other commonly used nanofluids. High thermal conductivity enhancement with moderate viscosity and good stability results was obtained for the Hal nanofluid.
\end{abstract}

(c) 2014 Elsevier B.V. All rights reserved.

\section{Introduction}

A technological approach to reduce energy consumption is to enhance performance of heat exchange systems. Heat transfer plays an important role in many fields such as power generation, chemical processes, air conditioning, transportation, microelectronics and any application in which heating and cooling processes are involved. The enhanced efficiency would allow reducing the size of the devices and decrease the operating costs of associated processes (Fan and Wang, 2011; Godson et al., 2010; Özerinç et al., 2010).

One of the parameters limiting the performance of heat exchange systems is the inherent low thermal conductivity of conventional heat transfer fluids. In the last years intensive research efforts have increased to solve this problem. As possible alternative could be the addition of solid particles with thermal conductivity higher than that of the fluid. In 19th century, Maxwell first dispersed small particles into a base fluid (Maxwell, 1873). Further works demonstrated that the addition of micrometer- or millimeter-sized particles enhances heat transfer properties but it causes sedimentation of large particles, clogging of flow channels, erosion of pipelines and pressure drops. This problem can be solved by adding nanoparticles (colloidal particles with main size smaller than $100 \mathrm{~nm}$ ) into the base fluid. High specific surface of nanoparticles, high dispersion stability, reduced particle clogging and adjustable properties make nanofluids an interesting solution to

\footnotetext{
* Corresponding author. Tel.: + 34964728193.

E-mail address: lcabedo@uji.es (L. Cabedo).
}

enhance the performance of heat exchange systems (Buongiorno et al., 2009; Li et al., 2009; Özerinç et al., 2010; Saidur et al., 2011).

Due to advances in nanotechnology, Masuda et al. (1993) first dispersed alumina $\left(\mathrm{Al}_{2} \mathrm{O}_{3}\right)$ ultrafine particles (13 nm in the mean diameter) in water, increasing thermal conductivity by $30 \%$. Choi (1995) proposed the concept of nanofluid (dilute dispersions with solid particles smaller than $100 \mathrm{~nm}$ ) to enhance thermal conductivity. Lee et al. (1999) dispersed alumina and copper oxide (CuO) nanoparticles in water and ethylene glycol (EG). These authors found that thermal conductivity increased linearly with the volume fraction. Nanofluid attention grew when Eastman et al. (2001) reported their results in nanofluids with copper $(\mathrm{Cu})$ nanoparticles and EG as base fluid. They found a substantial enhancement of thermal conductivity. The same year Choi et al. (2001) dispersed multiwall carbon nanotubes (MWCNT) in water measuring an enhancement up to $160 \%$ at only $1 \%$ volume fraction of MWCNT. From this moment, there have been many studies in three kinds of nanoparticles dispersed in heat transfer fluids, namely metallic particles as aluminum (Al) (Murshed et al., 2008) and gold (Au) (Putnam et al., 2006), CNT (Biercuk et al., 2002; Segarra et al., 2013; Xie et al., 2003), and non-metallic particles as silica $\left(\mathrm{SiO}_{2}\right)$, alumina $\left(\mathrm{Al}_{2} \mathrm{O}_{3}\right)$ (Mondragon et al., 2013) and titania $\left(\mathrm{TiO}_{2}\right)$ (Murshed et al., 2005). The convective heat transfer coefficient has been also studied (Juliá et al., 2012; Kim et al., 2009a,b).

However, different results and trends were found for the same materials characterized by different researchers, depending mainly in the procedure followed to prepare the nanofluids and the final state of agglomeration of the solid particles. In order to compare the values of thermal conductivity obtained by different researchers, a benchmark 
study was carried out (Buongiorno et al., 2009). The same samples of $\mathrm{Al}_{2} \mathrm{O}_{3}, \mathrm{SiO}_{2}$, Au and $\mathrm{Mn}-\mathrm{Zn}$ ferrite nanofluids were analyzed by several laboratories, at room temperature (ranging from 20 to $30^{\circ} \mathrm{C}$ ), using the different available techniques, so the results could be compared and experimental error could be determined.

The lack of agreement between experimental results and theory has inspired efforts in identifying responsible heat transfer mechanisms (Fan and Wang, 2011): (1) liquid-layering, (2) aggregation, (3) particle motion, and (4) others. The second mechanism stimulates phonons transference along large particles or particle aggregates, which involves that particles with large aspect ratio have better heat transfer properties (Fan and Wang, 2011; Ghosh et al., 2013; Özerinç et al., 2010). As a result, the size and shape of nanoparticles and clusters formed are the key factors for the thermal conductivity enhancement (Gao et al., 2009; Prasher et al., 2006; Shima et al., 2010; Warrier et al., 2010; Wu et al., 2010). It was demonstrated that chain-like structures and nanotubes or nanofibers provide the highest thermal conductivity. Because of this, researches have focused on the use of carbon nanotubes to enhance thermal properties of fluids (Ding et al., 2006; Garg et al., 2009; Kim et al., 2009a,b; Talaei et al., 2011).

Although the addition of nanoparticles improves the thermal properties and heat transfer capabilities of fluids, the industrial applicability of nanofluids in heat transfer systems is limited by the increase of the viscosity of the fluid (which increases the pumping power). However, as also occurred with the conductivity measurement, the viscosity of nanofluids is highly dependent on the degree of agglomeration of the particles so that very different results can be obtained depending on the particle size and shape, being the chain-like structures those presenting the highest viscosities. Therefore, the use of carbon nanotubes is limited by its high viscosity. Hence, the combined study of thermal properties (thermal conductivity and specific heat) and rheological properties (viscosity) is of great importance, although only few works include rheological measurements of nanofluids (Lee et al., 2008; Pastoriza-Gallego et al., 2009, 2011; Yu et al., 2012). As it was done for thermal conductivity, a benchmark study was carried out (Venerus et al., 2010), in order to compare the values of viscosity obtained by different researchers, when the same samples of $\mathrm{Al}_{2} \mathrm{O}_{3}, \mathrm{SiO}_{2}$, and $\mathrm{Mn}-\mathrm{Zn}$ ferrite nanofluids were analyzed by several laboratories, at room temperature (ranging from 20 to $26^{\circ} \mathrm{C}$ ).

One of the challenges in thermal applications is to find a nanofluid providing the best thermal conductivity to viscosity ratio thus increasing the efficiency of heat transfer processes. Recently, thanks to its structure and properties, halloysite (Hal) nanotubes have increased their interest for the nanotechnology of advanced materials in areas such as catalysis, drug delivery, biomedical implants, corrosion protection of metals, biosensors, organic synthesis, flame retardant coatings, specific ion adsorbents, materials for sustained release of herbicides and antimicrobials and energy storage devices (Deen et al., 2012). Hal is a clay mineral of the kaolin group, having a hollow tubular-like structure with particle sizes within the nanometrical size range and large aspect ratio. The outer diameter of typical Hal nanotubes is within the range of 15-100 nm, and length is between 500 and $1500 \mathrm{~nm}$ (Alhuthali and Low, 2013; Cavallaro et al., 2012; Lvov et al., 2008; Pasbakhsh et al., 2013; Vergaro et al., 2010). The size and shape of Hal nanotubes together with its chemical composition and structure make this material a good candidate to be dispersed in water, thus obtaining an interesting nanofluid for heat transfer applications. Other interesting applications of Hal nanotubes are as carriers for drug delivery, adsorbents and fillers in clay polymer nanocomposites (Tan et al., in press)

In the present work, the suitability of using Hal nanotubes-water nanofluids as heat transfer fluids is studied. To the best of our knowledge this is the first work using Hal as a nanoparticle for obtaining a nanofluid to be used in heat transfer applications. The solid powder was first characterized by means of SEM, TEM, WAXS, FTIR and TGA. Then nanofluids at different nanoparticle volume fractions (from 0.5 to $5 \%$ ) were prepared and their thermal conductivity, specific heat and viscosity were measured at different temperatures $\left(40,60\right.$ and $\left.80^{\circ} \mathrm{C}\right)$. In order to evaluate the suitability of this as a good heat transfer nanofluid the Prandtl number (Pr) was obtained. Prandtl number $\left(\operatorname{Pr}=\eta_{\mathrm{nf}} \cdot C_{\mathrm{p}, \mathrm{nf}} / k_{\mathrm{nf}}\right)$ compares thermal properties like specific heat $\left(C_{\mathrm{p}, \mathrm{nf}}\right)$ and thermal conductivity $\left(k_{\mathrm{nf}}\right)$, with viscosity $\left(\eta_{\mathrm{nf}}\right)$. Experimental results showed that Hal nanotubes-water nanofluids present good characteristics to be considered as heat transfer fluids: high conductivity and moderate viscosity. Moreover, nanofluids were checked to remain stable for at least $24 \mathrm{~h}$.

\section{Materials and methods}

\subsection{Materials}

Tests were carried out with Hal nanotubes. Chemical formula of Hal is $\mathrm{Al}_{2} \mathrm{Si}_{2} \mathrm{O}_{5}(\mathrm{OH})_{4} \cdot \mathrm{nH}_{2} \mathrm{O}$, where $n=0-2$. Anhydrous form of Hal $(n=0)$ has a basal spacing of $0.7 \mathrm{~nm}$, while hydrated form $(n=2)$ has a basal spacing of $1 \mathrm{~nm}$ (Deen et al., 2012; Lvov et al., 2008; Rozynek et al., 2013). Outer surface of Hal nanotubes consists of tetrahedral siloxane groups ( $\mathrm{Si}-\mathrm{O}-\mathrm{Si})$, whereas inner consists of aluminol groups $(\mathrm{Al}-\mathrm{OH})$ (Alhuthali and Low, 2013; Kadi et al., 2012). Neighborhood of aluminol and siloxane layers provides a highly disordered structure with random dislocations and shifts, which rolls up the multilayer forming the hollow tubular form (Vergaro et al., 2010; Alhuthali and Low, 2013; Rozynek et al., 2013).

The powder used in this work was supplied by the U.S. company "NaturalNano, Inc." According to the manufacturer, Hal nanotube composition is between 98 and $99.8 \%$ of Hal. Hal nanotubes are ultra-tiny hollow tubes with diameters typically smaller than $100 \mathrm{~nm}$, with lengths typically ranging from about $500 \mathrm{~nm}$ to over $1.2 \mu \mathrm{m}$.

Nanofluids with different volume concentrations $(0.5,1,3$ and 5\%) were prepared by adding distilled water to the defined amounts of nanoparticles. In this method, known as the two-step method, the nanoparticles are purchased in dry powder and then dispersed in the liquid medium. The dispersion was made using an ultrasonic probe (HD2200 Sonopuls, Bandelin) and the mixture was submitted to a sonication treatment for $2 \mathrm{~min}$. Afterwards, the $\mathrm{pH}$ of the nanofluid was modified by adding $\mathrm{HCl}$ or $\mathrm{NaOH}$ solutions ( $10 \%$ mass) in order to modify the surface charges of the particles and to electrostatically stabilize the dispersion. Finally, to ensure a correct dispersion of all the components, the nanofluids were submitted to a second sonication treatment during 2 min.

\subsection{Experimental methods}

Scanning electron microscopy (SEM) was performed in a Leica-Zeiss LEO 440 microscope equipped with digital image acquisition. Powder samples were observed so the morphology and size of the raw material were determined.

Transmission electron microscopy (TEM) images were obtained using a JEOL 2100 microscope at an operating voltage of $100 \mathrm{kV}$. TEM was used to observe the morphology and size of Hal nanotubes and clusters in the dispersion. In order to do this, a small amount of the sample was dropped on a copper grid and then was dried to remove the liquid. To prevent large agglomeration of particles during the drying of the sample very diluted nanofluids were prepared.

Wide angle X-ray scattering experiments (WAXS) were performed using a Bruker AXS D4 Endeavor diffractometer. Radial scans of intensity versus scattering angle $(2 \theta)$ were recorded at room temperature in the range $2-30^{\circ} 2 \theta$ (step size $=0.02^{\circ} 2 \theta$, scanning rate $=8 \mathrm{~s} / \mathrm{step}$ ) with identical setting of the instrument by using filtered CuKa radiation $(\lambda=1.54 \AA$ ), an operating voltage of $40 \mathrm{kV}$, and a filament current of $30 \mathrm{~mA}$. To calculate the clay mineral $d$-value, Bragg's law $(\lambda=2 \mathrm{~d}$ $\sin \theta$ ) was applied.

Fourier transform infrared (FTIR) spectra were collected for the Hal powder using a Jasco FT/IR-6200 spectrometer in attenuated total 
reflection (ATR) mode. The FTIR-ATR instrument was operated in the wavenumber range of $600-4000 \mathrm{~cm}^{-1}$, with a diamond/ZnSe crystal, 32 scans and resolution of $4 \mathrm{~cm}^{-1}$. A background scan of clean diamond/ZnSe crystal was acquired before scanning the samples.

Thermogravimetric (TGA) tests were carried out using a TG-STDA Mettler Toledo thermogravimetric analyzer. Samples of approximately $15-20 \mathrm{mg}$ were scanned from 50 up to $900{ }^{\circ} \mathrm{C}$ at $10 \mathrm{~K} / \mathrm{min}$. All scans were performed with a flow of $50 \mathrm{~cm}^{3} / \mathrm{min}$ of nitrogen.

The zeta potential $(\psi)$ was measured using a Zetasizer Nano ZS (Malvern Instruments Ltd., UK) from the electrophoretic mobility of particles when an electric field is applied. This velocity was measured using laser Doppler velocimetry (LDV) and the zeta potential was obtained through the Henry equation.

The particle size distributions $\left(d_{\mathrm{p}}\right)$ were determined by dynamic light scattering (DLS) using a Zetasizer Nano ZS (Malvern Instruments Ltd., UK). Particle size was measured from the velocity of the particles due to their Brownian motion by means of the Einstein-Stokes equation.

The thermal conductivity $(k)$ of all nanofluids was measured using a KD2 Pro conductimeter (Decagon Devices Inc.). The KD2 Pro is the commercial device that measures the thermal conductivity with the help of the transient hot wire technique. In this method, a thin metallic wire is embedded in the test liquid acting as both heat source and temperature sensor. The transient hot wire technique works by measuring the temperature/time response of the wire to an abrupt electrical pulse. The thermal conductivity of the test sample can be derived from the temperature change of the hot wire over a specific time interval. The sample was introduced in a sealed glass tube $(20 \mathrm{ml})$ where the sensor was inserted vertically. To carry out the test at high temperature conditions the tube was submerged in a thermostatic bath where the temperature was controlled. A period of time of $1 \mathrm{~h}$ was waited for the sample to reach the desired temperature before any test. After that time, six measurements were done for each nanofluid sample. Within the measurement time the bath was switched off to avoid vibrations. It was important to wait for about 15 min between readings to recover the temperature reached after the heat pulse applied to the nanofluid.

The KD2 Pro uses special algorithms to analyze measurements made during a heating and a cooling interval. The device was specially design to measure the thermal conductivity of solids or liquids at low temperatures where the temperature is not affected by external changes. However, in this case the sample was introduced in a bath, and when the bath was switched off to avoid vibrations, the decrease of the bath temperature during the reading time influenced the evolution of the fluid temperature when the heat pulse was applied. Therefore, the internal equations of the KD2 Pro and the values registered by it could not be used to fit the data, as those influences and contributions were not taken into account. Experimental data for the evolution of the temperature due to the heat pulse were fitted to the following equation:

$T=m_{0}+m_{1} t+m_{2} \ln t$

where $m_{0}$ is the ambient temperature during heating, $m_{1}$ is the rate of background temperature drift and $m_{2}$ is the slope of a line relating temperature rise to logarithm of time. The thermal conductivity can be computed from the parameter $m_{2}$ :

$k_{\mathrm{nf}}={\frac{q}{4 \pi m_{2}}}^{k=\frac{q}{4 \pi m_{3}}}$

where $k_{\mathrm{nf}}$ is the thermal conductivity and $q$ is the power of the heat pulse applied.

Differential scanning calorimetry (DSC) measurements were carried out to determine the specific heat $\left(C_{\mathrm{p}}\right)$ for each nanofluid using DSC1 instrument (Mettler Toledo, USA). The sequence used in the specific heat determination was as follows: isotherm of $5 \mathrm{~min}$ at $25{ }^{\circ} \mathrm{C}$, dynamic segment from 25 to $85{ }^{\circ} \mathrm{C}$ at a heating rate of $10{ }^{\circ} \mathrm{C} / \mathrm{min}$ and isotherm of
5 min at $85{ }^{\circ} \mathrm{C}$. As a consequence of the nature of the sample (liquid), the crucible (aluminum) was sealed in order to avoid loss of material by evaporation. Previous to the sample tests, a blank measurement was run with an empty cell following the same treatment in order to counterbalance the measuring cell calorimetric response. Heat flow measurements were calibrated with indium and zinc calibration standards in the whole temperature range, thus providing a $5 \%$ error in the specific heat measurements.

The viscosity $(\eta)$ and rheological behavior of nanofluids were obtained by conducting tests under steady state conditions using a Haake RheoStress 1 rotational rheometer (Thermo Scientific). A system composed of two concentric cylinders was used. In the gap between the inner cylinder (diameter $=34 \mathrm{~mm}$ ) and the outer cylinder (diameter $=36.88 \mathrm{~mm}$ ) $40 \mathrm{ml}$ of sample was introduced. Before each test, a pre-treatment, in which the samples were submitted to a constant shear stress, was applied to the nanofluids for $30 \mathrm{~s}$ to ensure similar starting conditions for all the measurements.

The stability of the nanofluids was analyzed through the evolution of the amount of light backscattered by the nanofluid from an incident laser beam. Measurements were based on the multiple light scattering theory (Amiri et al., 2009; Mondragon et al., 2012). Stability in colloid science is used not only in the thermodynamic sense but also in a strictly colloidal sense. "Colloidally stable" means that the colloidal particles do not settle and do not agglomerate at a significant rate (Bergna and Roberts, 2006). The experimental device consists of a laser beam and a detector that measures the light transmitted by the sample. For each nanofluid, the transmission profiles were obtained at different heights along the cell. To analyze the stability of nanofluids the measurements were carried out at different time intervals up to a total time of $24 \mathrm{~h}$.

\section{Results and discussion}

\subsection{Halloysite characterization}

Hal nanotubes acquired in dry powder were characterized so that the morphology, size, internal structure, chemical composition and thermal stability were determined, previous to the production of nanofluids.

Figs. 1 and 2 report, respectively for SEM and TEM, images of the tubular morphology of Hal nanotubes. The platy particles observed in the SEM image can be attributed to residual kaolinite. Image treatment of the micrographs allowed determining the mean diameter and the mean length of the nanotubes, which have been found to be 0.09 and $1.31 \mu \mathrm{m}$, respectively, being thus the calculated aspect ratio of ca. 14.5. In the TEM micrograph (Fig. 2) the internal structure of the Hal is visible,

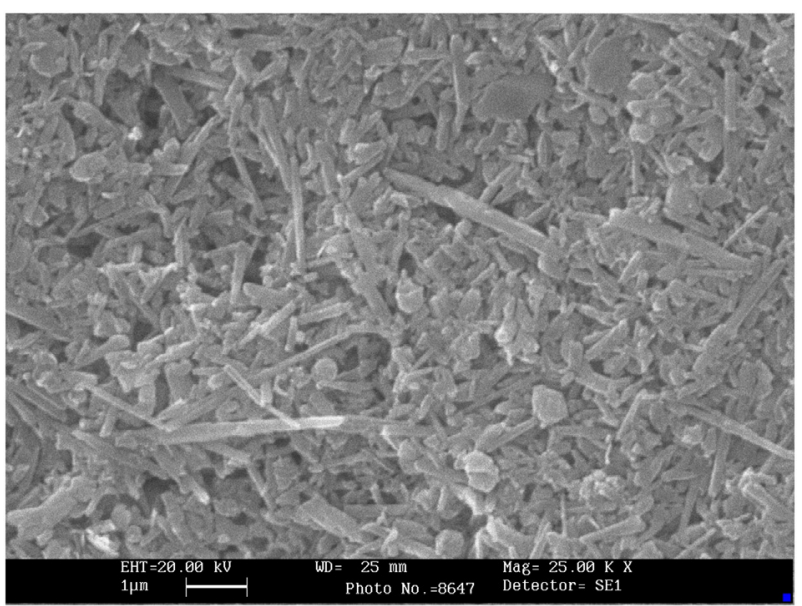

Fig. 1. SEM image of Hal nanotube powder 


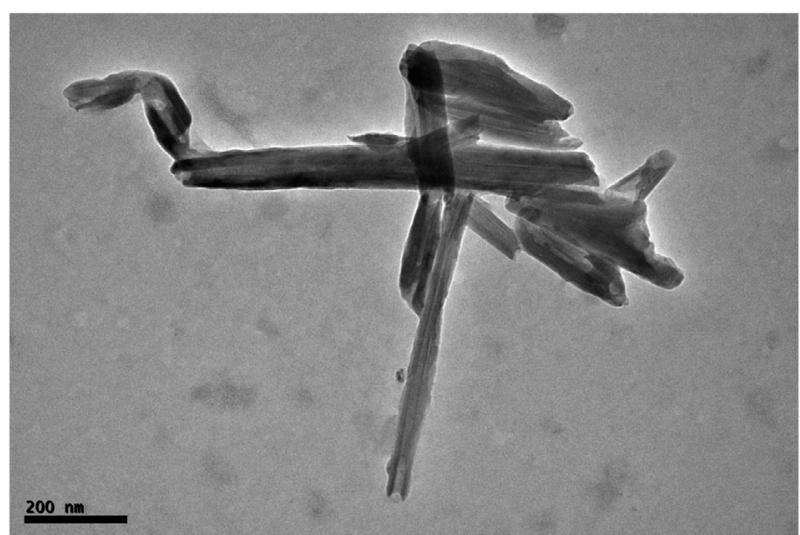

Fig. 2. TEM image of Hal nanotube powder.

i.e. the stacking of the clay mineral layers in a hollow tubular-like particle.

WAXS pattern of the Hal is represented Fig. 3. Three characteristic reflections at $2 \theta$ values of $11.95^{\circ}, 20.15^{\circ}$ and $24.95^{\circ}$ can be detected. The former corresponds to basal reflection of the clay mineral, which by applying the Bragg's law yields a $d$-value of $0.74 \mathrm{~nm}$. This result suggests that the Hal is in anhydrous form (Alhuthali and Low, 2013; Cheng et al., 2010; Kadi et al., 2012; Lvov et al., 2008; Rozynek et al., 2013; Zhang et al., 2012). The peak at $20.15^{\circ} 2 \theta$ can be ascribed to the 020 reflection, while the one at $24.95^{\circ} 2 \theta$ is the 002 . The lack of clear peaks in the range from the 020 reflection to 002 suggests a big structural disorder (Rozynek et al., 2013).

FTIR-ATR experiments of the Hal powder were also performed and the spectrum is plotted in Fig. 4. In it hydroxyl groups of aluminol present in the inner layer can be identified; specifically vibration at $3620 \mathrm{~cm}^{-1}$ can be assigned to the $\mathrm{O}-\mathrm{H}$ stretching of inner hydroxyl groups, while the band at $3696 \mathrm{~cm}^{-1}$ can be attributed to stretching of inner-surface hydroxyl groups (Cheng et al., 2010; Kadi et al., 2012; Yuan et al., 2012). Peak at $1593 \mathrm{~cm}^{-1}$ is attributed to bending vibrations of absorbed water (Cheng et al., 2010; Frost et al., 1998; Kadi et al., 2012). In the 1300 to $500 \mathrm{~cm}^{-1}$ range, the peak at $1117 \mathrm{~cm}^{-1}$ is assigned to stretching mode of apical $\mathrm{Si}-\mathrm{O}$ bonds, while the bands at 1030 and $907 \mathrm{~cm}^{-1}$ are caused by the stretching vibrations of $\mathrm{Si}-\mathrm{O}-\mathrm{Si}$ and bending modes of $\mathrm{Al}-\mathrm{O}-\mathrm{H}$. The bands at 796 and $7466 \mathrm{~cm}^{-1}$ correspond to $\mathrm{OH}$ translation vibrations of Hal (Cheng et al., 2010).

Thermal stability of Hal nanotubes measured by TGA is plotted in Fig. 5. Tests were carried out within the temperature range of 50-

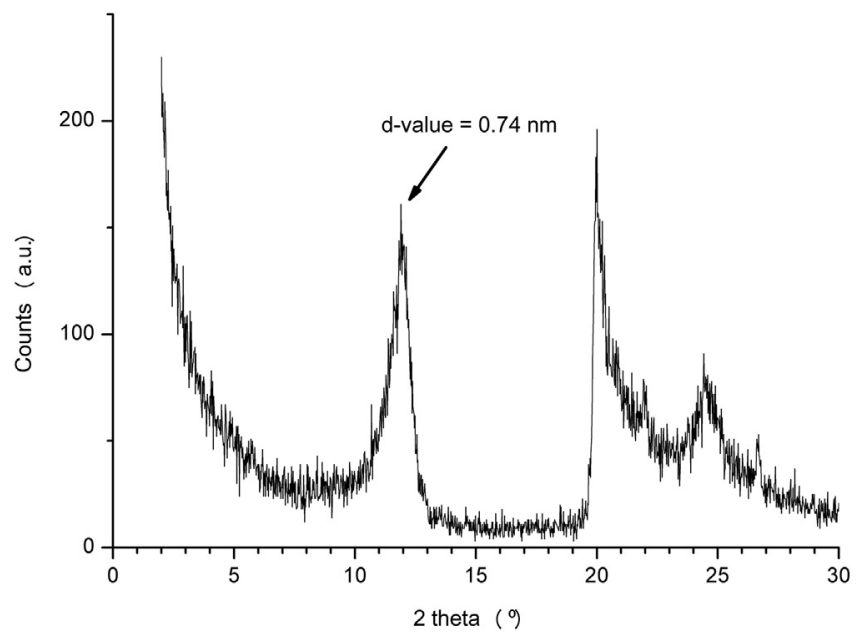

Fig. 3. Hal pattern measured by WAXS.

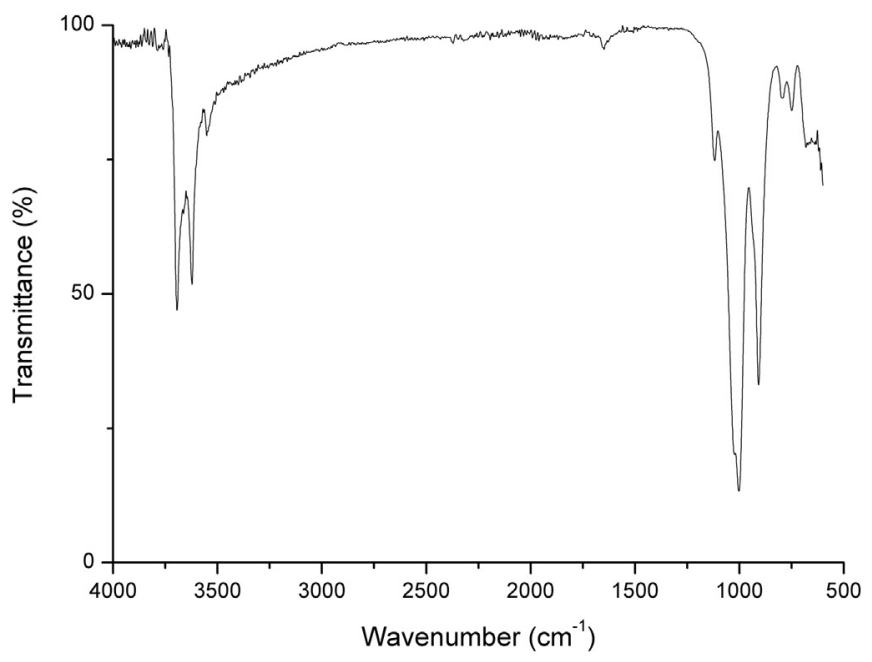

Fig. 4. Hal spectrum obtained by FTIR-ATR.

$900{ }^{\circ} \mathrm{C}$. Weak absorbed water to particle surface is easily removed at temperatures slightly above $60{ }^{\circ} \mathrm{C}$. Above $200{ }^{\circ} \mathrm{C}$ there is a little slope of mass loss due to the removing of water physisorbed at e.g. the micropores of clay (Frost and Vassallo, 1996; Kadi et al., 2012; Nicolini et al., 2009; Rozynek et al., 2013). The most important mass loss takes place at $490{ }^{\circ} \mathrm{C}$, due to the dehydroxylation of the aluminol layers in the Hal.

\subsection{Nanofluid characterization}

One of the main characteristics that make nanofluids of interest is their high stability. In order to prepare stable water based dispersions, nanoparticles have to be electrostatically stabilized by adjusting the $\mathrm{pH}$ value. For each system and chemical substance there is a $\mathrm{pH}$ value at which the surface charge in the shear plane that surrounds the particle takes a value of zero and particles agglomerate when get approach. This pH is known as isoelectric point (IEP) (Hunter, 1988). Consequently, to prepare well-stabilized dispersions, $\mathrm{pH}$ values far away from the IEP are needed.

To determine the IEP of the nanofluids, the zeta potential of dispersions prepared at $\mathrm{pH}$ values of 2, 4, 6, 8, 10 and 12 was measured. All the measurements were carried out in dilute dispersion at a $0.5 \%$ volume fraction. The $\mathrm{pH}$ value was modified by addition of $\mathrm{HCl}$ and $\mathrm{NaOH}$. Fig. 6 plots the Z-potential values obtained versus the $\mathrm{pH}$ value for each nanofluid prepared. According to these results, the nanofluid's Z-potential reaches a zero value at $\mathrm{pH}=3.5$ close to that of the silica

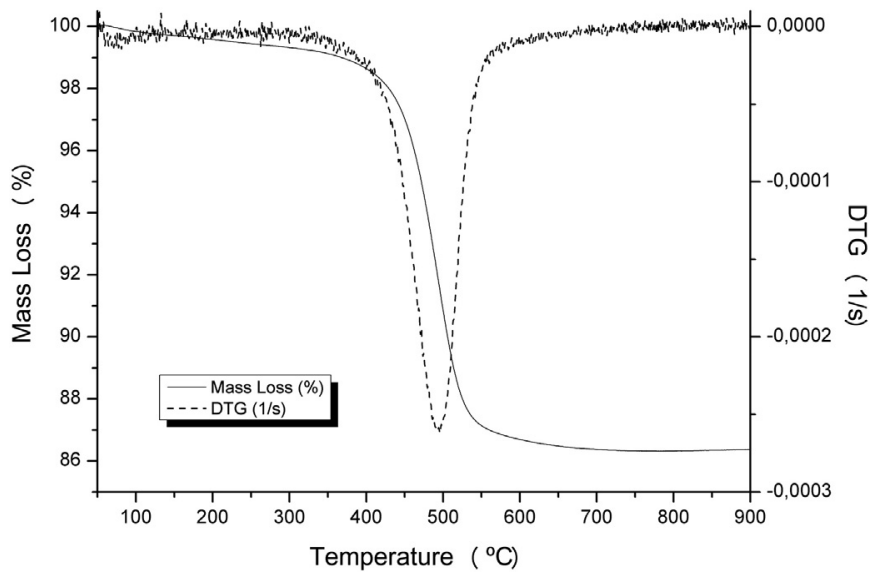

Fig. 5. TGA and DTG curves obtained for Hal. 


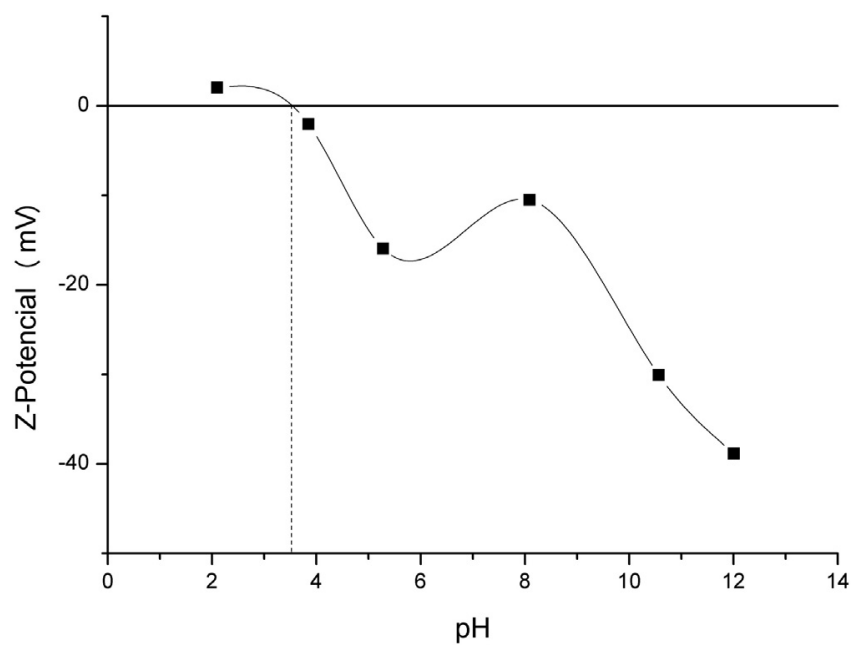

Fig. 6.Z-potential curve as a function of $\mathrm{pH}$ value for Hal nanofluid at $0.5 \%$ volume fraction.

$(\mathrm{IEP}=2)$. At $\mathrm{pH}=8$ there is a slight increase which can be attributed to the aluminol surface (which has an IEP of 9). The silica behavior is more pronounced than that of alumina because is located on outer surface (Deen et al., 2012; Zhang et al., 2012). Therefore, the IEP for Hal nanotubes is located at $\mathrm{pH}=3.5$ and the $\mathrm{pH}$ value at which the nanofluid reaches the highest stability is located at $\mathrm{pH}=12$ with a corresponding Z-potential value of about $-39 \mathrm{mV}$. The other tested nanofluids were also prepared at this $\mathrm{pH}$ value to ensure stability.

The stability of the nanofluid prepared at $0.5 \%$ volume fraction and $\mathrm{pH}=12$ was checked through the evolution with time of the amount of light transmitted by the sample at different sample heights. The ratio between the light backscattered at a certain time and the corresponding value at $t=0$ for different heights is plotted in Fig. 7. As it can be concluded from the measurements, the values do not change significantly either with time or with height, thus proving the stability of the dispersion. As a result, the stability of nanofluids at $\mathrm{pH}=12$ can be guaranteed for at least $24 \mathrm{~h}$.

Particle size distribution in number for the dispersion containing $0.5 \%$ volume fraction of Hal nanotubes was measured with DLS and is

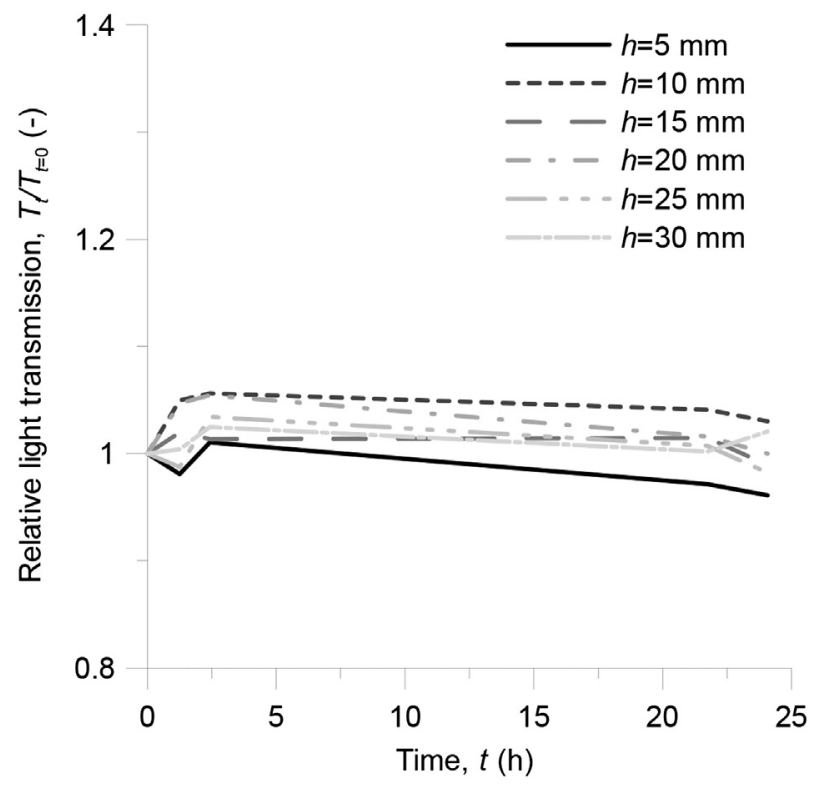

Fig. 7. Evolution with time of light transmission profiles of Hal nanofluid at $\mathrm{pH}=12$.

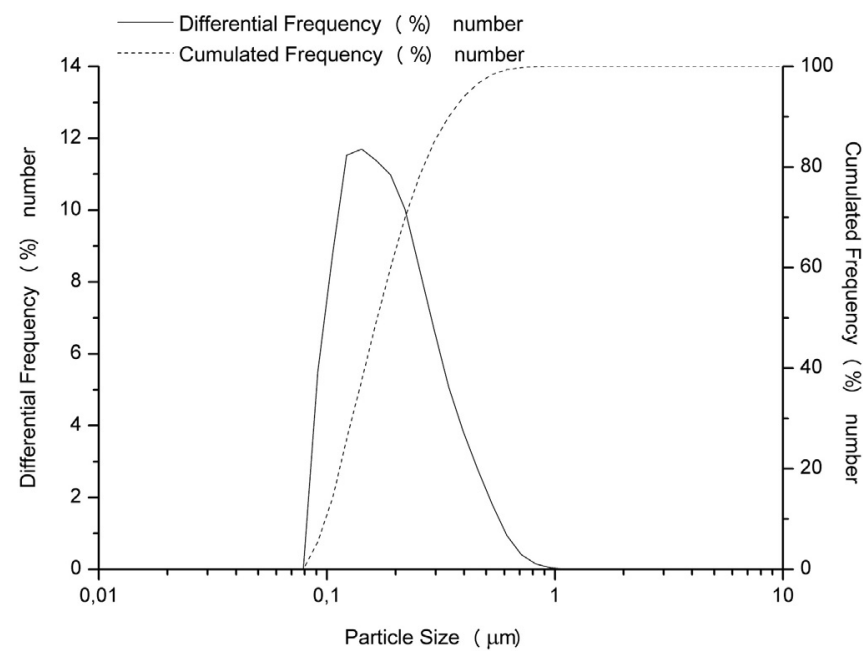

Fig. 8. Particle size distribution of Hal nanofluid at $0.5 \%$ volume fraction.

represented in Fig. 8. This plot exhibits a monomodal distribution and its shape is representative of all the studied nanofluids (volume fractions $0.5,1,3$ and $5 \%)$. The characteristic diameters $\left(d_{10}, d_{50}\right.$ and $\left.d_{90}\right)$, as obtained from the respective curves, can be found in Table 1 for the different volume fraction percentages. The dispersion containing $0.5 \%$ of Hal nanotubes exhibited a $d_{50}$ of $0.180 \mu \mathrm{m}$. This value is almost 10 times smaller than the average length of the nanotubes, as determined by SEM observation. However, the mean particle size is bigger than the nanotube diameter, being thus this $d_{50}$ value the size of an aggregated structure, i.e. a Hal nanotube cluster. This means that nanotubes dispersed in water are not perfectly dispersed but forming clusters. The mean size and size distribution width decrease when the solid content is increased, probably revealing a decrease in the average cluster diameter size.

\subsection{Thermophysical properties of nanofluids}

The evolution of the thermal conductivity, specific heat and viscosity of base fluid and Hal nanofluids at different solid content $(0.5,1,3$ and $5 \%$ volume fraction) and temperature $\left(40,60\right.$ and $\left.80{ }^{\circ} \mathrm{C}\right)$ was measured and studied.

The thermal conductivity enhancement $\left(k_{\mathrm{r}}\right)$ was calculated dividing nanofluid and base fluid thermal conductivities ( $k_{\mathrm{nf}}$ and $k_{\mathrm{bf}}$ respectively). The evolution of the thermal conductivity enhancement of all tested nanofluids, together with the bar error corresponding to the six experimental measurements for each condition, is plotted in Fig. 9a. Thermal conductivity increases with solid content due to the higher number of particles present in the dispersion and the higher number of contacts between them (Keblisnki et al., 2001). For very low solid contents, the degree of dispersion is higher and the addition of nanoparticles to the base fluid does not provide a significant increase in the thermal conductivity. To obtain an increase in the thermal conductivity related to the base fluid, solid contents higher than $1 \%$ are needed. The maximum thermal conductivity enhancement achieved at $5 \%$ volume fraction was of $8 \%$. As a general trend, thermal conductivity decreases with temperature, although significant differences were not found.

Table 1

Characteristic diameters of particle size distribution for different solid content.

\begin{tabular}{llll}
\hline Volume fraction $(\%)$ & $d_{10}(\mu \mathrm{m})$ & $d_{50}(\mu \mathrm{m})$ & $d_{90}(\mu \mathrm{m})$ \\
\hline 0.5 & 0.11 & 0.18 & 0.38 \\
1 & 0.06 & 0.08 & 0.2 \\
3 & 0.013 & 0.02 & 0.02 \\
5 & 0.011 & 0.02 & 0.02 \\
\hline
\end{tabular}



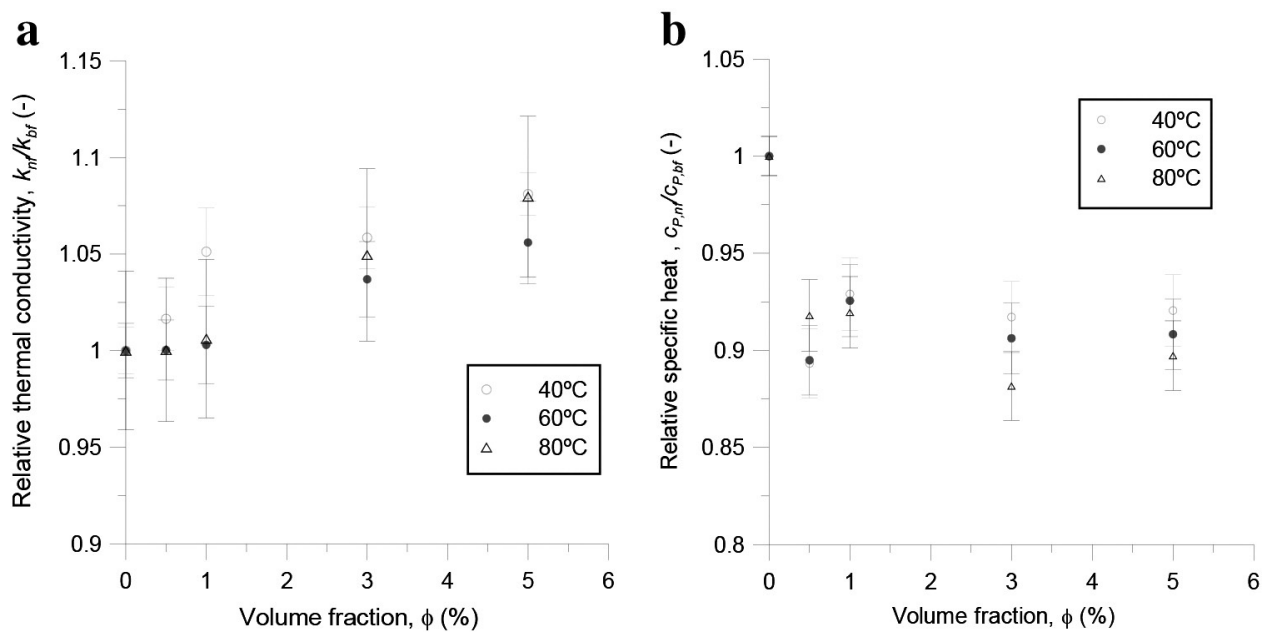

Fig. 9. Evolution of (a) relative thermal conductivity and (b) relative specific heat with volume fraction and temperature.

Specific heat capacity of all prepared nanofluids was experimentally measured at different solid content and temperature conditions. Evolution of the relative specific heat between nanofluid $\left(C_{\mathrm{p}, \mathrm{nf}}\right)$ and base fluid $\left(C_{\mathrm{p}, \mathrm{bf}}\right)$ with these two variables is presented in Fig. $9 \mathrm{~b}$. The specific heat describes the amount of heat required to increase the temperature of the sample by a given amount. As expected, the specific heat decreases with the addition of Hal, due to the lower specific heat of the solid phase with respect to that of the liquid phase. However, the evolution with solid content and temperature is negligible and differences can be attributed to the experimental error.

Fig. 10a shows the rheological behavior of nanofluids at $T=40^{\circ} \mathrm{C}$. Shear stress varies linearly with shear rate according to Newton's law and it can be concluded that nanofluids behave newtonian. When temperature is increased, viscosity decreases while keeping the same behavior (not shown in the figure). From these data, viscosity of nanofluids is obtained by means of the Newton's law. Fig. 10b shows the evolution of the relative viscosity of the nanofluids with solid content and temperature. Viscosity ratio was calculated from nanofluid and base fluid viscosities ( $\eta_{\mathrm{nf}}$ and $\eta_{\mathrm{bf}}$ respectively). The viscosity of the nanofluid increases with solid content according to the models available in literature (Quemada, 1977). As the solid content increases, there exists more interaction between particles so that clusters are formed providing a higher viscosity. Besides, the increment of viscosity is more important for high temperature conditions, meaning that the influence of temperature is different between nanofluids and base fluid. The nanofluid presenting the highest thermal conductivity enhancement is also the one with the highest viscosity (65\% enhancement over the base fluid).

In order to evaluate if Hal nanofluids are appropriate to be used as heat transfer fluids, providing a good thermal behavior with lowest penalty in viscosity (pumping power), Prandtl number $\left(P r=c_{\mathrm{P}} \cdot \eta / k\right)$ was calculated by using all physical properties measured at different experimental conditions. This dimensionless number represents the ratio between viscous and thermal forces. Low values of the Prandtl number indicate high thermal conductivity together with moderate viscosities. In Fig. 11a evolution of relative Prandtl number with solid content and temperature is shown for Hal nanofluids. Prandtl number increases with solid content as thermal conductivity and viscosity also present similar trends.

In Fig. 11b, relative Prandtl numbers of Hal nanotubes at $80{ }^{\circ} \mathrm{C}$ are compared to previous experimental results (Mondragon et al., 2013) for different nanofluids ( silica, alumina and carbon nanotubes). It can be concluded that Hal nanofluids present the lowest values of Prandtl number. These and the previous experimental results (Mondragon et al., 2013) indicate that viscosity is the most important variable for Prandtl number. Therefore, similar thermal conductivity enhancement could be achieved for Hal nanotubes but with lower viscosities than

Fig. 10. (a) Rheological behavior of nanofluids at $T=40^{\circ} \mathrm{C}$. (b) Evolution of relative viscosity with volume fraction and temperature. 

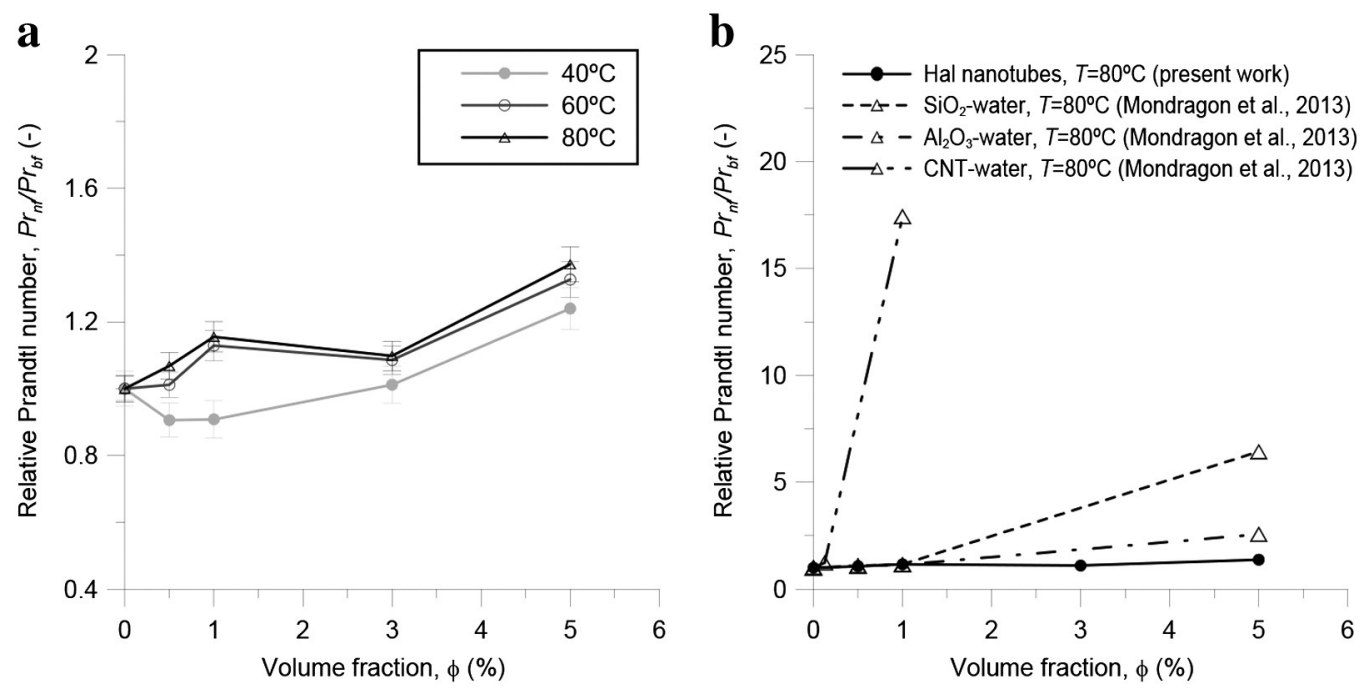

Fig. 11. Evolution of relative Prandtl number with volume fraction for (a) Hal nanotubes and (b) different nanofluids.

for metal oxides and carbon nanotubes. Hal nanotubes combine two positive characteristics: the tubular morphology leads to good thermal conductivity while the chemical composition leads to a better dispersion in water and low viscosity. As a result, Hal nanofluids can be considered to be used as heat transfer fluid.

\section{Conclusions}

In the present study Hal nanotubes were studied as a potential nanoparticle for obtaining water-based nanofluids for heat transfer applications. Initially the clay mineral was studied in powder form by means of SEM, TEM, WAXS, FTIR and TGA, revealing the results a high purity, a well-defined tubular shape and a large aspect ratio.

The stability of the nanofluid was proved by light transmission measurements. Particle size and particle size distribution of nanotubes in water were experimentally measured, revealing formation of clusters and a decrease in the cluster size with increasing solid contents.

Thermophysical properties were analyzed in order to evaluate the capability of Hal nanofluids to be used as heat transfer fluid, revealing an increase in thermal conductivity with solid content up to an $8 \%$ for the nanofluid at $5 \%$ of Hal nanotubes volume fraction and $T=80^{\circ} \mathrm{C}$. Viscosity also increased with solid content, while the specific heat of nanofluids decreased when nanoparticles were introduced. Finally, the Prandtl number was calculated, revealing that Hal nanofluids have a good thermal behavior and lower Prandtl numbers compared to other nanofluids. This could be explained due to the tubular morphology leading to a good thermal conductivity and the chemical composition leading to a better dispersion in water and low viscosity. In conclusion, Hal nanofluids can be considered to be used as heat transfer fluid.

\section{Acknowledgments}

The authors gratefully acknowledge the financial support from the Spanish Ministry of Science and Innovation (project CTQ2010-21321C02-02) and Universitat Jaume I (project P1-1B2013-43). The authors wish to thank Raquel Oliver, José Ortega and Salvador Torró for the experimental support.

\section{References}

Alhuthali, A., Low, I.M., 2013. Water absorption, mechanical, and thermal properties of halloysite nanotube reinforced vinyl-ester nanocomposites. J. Mater. Sci. 48, 4260-4273.

Amiri, A., Oye, G., Sjöblom, J., 2009. Influence of pH, high salinity and particle concentration on stability and rheological properties of aqueous suspensions of fumed silica. Colloids Surf. A Physicochem. Eng. Asp. 349, 43-54.
Bergna, H.E., Roberts, W.O., 2006. Colloidal Silica: Fundamentals and Applications. CRC Taylor \& Francis,

Biercuk, M.J., Llaguno, M.C., Radosavljevic, M., Hyun, J.K., Johnson, A.T., Fischer, J.E., 2002. Carbon nanotube composites for thermal management. Appl. Phys. Lett. 80, 2767-2769.

Buongiorno, J., et al., 2009. A benchmark study on the thermal conductivity of nanofluids. J. Appl. Phys. 106, 094312.

Cavallaro, G., Lazzara, G., Milioto, S., 2012. Exploiting the colloidal stability and solubilization ability of clay nanotubes/ionic surfactant hybrid nanomaterials. J. Phys. Chem. C 116, 21932-21938.

Cheng, H.F., Frost, R.L., Yang, J., Liu, Q.F., He, J.K., 2010. Infrared and infrared emission spectroscopic study of typical Chinese kaolinite and halloysite. Spectrochim. Acta A Mol. Biomol. Spectrosc. 77, 1014-1020.

Choi, S.U.S., 1995. Enhancing thermal conductivity of fluids with nanoparticles. ASME Int. Mech. Eng. Congress and Exp., San Francisco, CA, USA.

Choi, S.U.S., Zhang, Z.G., Yu, W., Lockwood, F.E., Grulke, E.A., 2001. Anomalous thermal conductivity enhancement in nanotube suspensions. Appl. Phys. Lett. 79, 2252-2254.

Deen, I., Pang, X., Zhitomirsky, I., 2012. Electrophoretic deposition of composite chitosanhalloysite nanotube-hydroxyapatite films. Colloids Surf. A Physicochem. Eng. Asp. $410,38-44$

Ding, Y., Alias, H., Wen, D., Williams, R., 2006. Heat transfer of aqueous suspensions of carbon nanotubes (CNT nanofluids). Int. J. Heat Mass Trans. 49, 240-250.

Eastman, J.A., Choi, S.U.S., Li, S., Yu, W., Thompson, L.J., 2001. Anomalously increased effective thermal conductivities of ethylene glycol-based nanofluids containing copper nanoparticles. Appl. Phys. Lett. 78, 718-720.

Fan, J., Wang, L.Q., 2011. Review of heat conduction in nanofluids. J. Heat Transfer Trans. ASME 133, 1-14.

Frost, R.L., Vassallo, A.M., 1996. The dehydroxylation of the kaolinite clay minerals using infrared emission spectroscopy. Clay Clay Miner. 44, 635-651.

Frost, R.L., Kristof, J., Paroz, G.N., Kloprogge, J.T., 1998. Role of water in the intercalation of kaolinite with hydrazine. J. Colloid Interf. Sci. 208, 216-225.

Gao, J.W., Zheng, R.T., Ohtani, H., Zhu, D.S., Chen, G., 2009. Experimental investigation of heat conduction mechanisms in nanofluids. Clue on clustering. Nano Lett. 9, 4128-4132.

Garg, P., Alvarado, J., Mord, C., 2009. An experimental study on the effect of ultrasonication on viscosity and heat transfer performance of multi-wall carbon nanotube-based aqueous nanofluids. Int. J. Heat Mass Trans. 52, 5090-5101.

Ghosh, M.M., Ghosh, S., Pabi, S.K., 2013. Effects of particle shape and fluid temperature on heat-transfer characteristics of nanofluids. J. Mater. Eng. Perform. 22, 1525-1529.

Godson, L., Raja, B., Lal, D.M., Wongwises, S., 2010. Enhancement of heat transfer using nanofluids-An overview. Renew. Sustain. Energy Rev. 14, 629-641.

Hunter, R.J., 1988. Zeta potential in colloid science. Principles and applicationsAcademic Press Limited,.

Juliá, J.E., Hernández, L., Martínez-Cuenca, R., Hibiki, T., Mondragón, R., Segarra, C., Jarque, J.C., 2012. Measurement and modelling of forced convective heat transfer coefficient and pressure drop of $\mathrm{Al}_{2} \mathrm{O}_{3}$ - and $\mathrm{SiO}_{2}$-water nanofluids. 6th European Thermal Sciences Conference, pp. 1-8.

Kadi, S., Lellou, S., Marouf-Khelifa, K., Schott, J., Gener-Batonneau, I., Khelifa, A., 2012. Preparation, characterisation and application of thermally treated Algerian halloysite. Microporous Mesoporous Mater. 158, 47-54.

Keblisnki, P., Phillpot, S.R., Choi, S.U.S., Eastman, J.A., 2001. Mechanisms of heat flow in suspensions of nano-sized particles (nanofluids). Int. J. Heat Mass Trans. 45, 855-863.

Kim, D., Kwon, Y., Cho, Y. Li, C. Cheong, S., Hwang, Y., Lee, J., Hong, D., Moon, S., 2009a. Convective heat transfer characteristics of nanofluids under laminar and turbulent flow conditions. Curr. Appl. Phys. 9, E119-E123.

Kim, N.-J., Park, S.-S., Lim, S.H., Chun, W., 2009b. A study on the characteristics of carbon nanofluids at the room temperature $\left(25^{\circ} \mathrm{C}\right)$. Int. Comm. Heat Mass Tran. 38 , 313-318.

Lee, S., Choi, S.U.S., Li, S., Eastman, J.A., 1999. Measuring thermal conductivity of fluids containing oxide nanoparticles. J. Heat Transfer Trans. ASME 121, 280-289. 
Lee, J.H., Hwang, K.S., Jang, S.P., Lee, B.H., Kim, J.H., Choi, S.U.S., Choi, C.J., 2008. Effective viscosities and thermal conductivities of aqueous nanofluids containing low volume concentrations of $\mathrm{Al}_{2} \mathrm{O}_{3}$ nanoparticles. Int. J. Heat Mass Tranfer 51, 2651-2656.

Li, Y.J., Zhou, J.E., Tung, S., Schneider, E., Xi, S.Q., 2009. A review on development of nanofluid preparation and characterization. Powder Technol. 196, 89-101.

Lvov, Y.M., Shchukin, D.G., Möhwald, H., Price, R.R., 2008. Halloysite clay nanotubes for controlled release of protective agents. ACS Nano 2, 814-820.

Masuda, H., Ebata, A., Teramae, K., Hishinuma, N., 1993. Alteration of thermal conductivity and viscosity of liquid by dispersing ultra-fine particles. Netsu Bussei 7, 227-233.

Maxwell, J., 1873. A treatise on electricity and magnetism. Oxford Univ. Press, London, p. 365.

Mondragon, R., Julia, J.E., Barba, A., Jarque, J.C., 2012. Characterization of silica-water nanofluids dispersed with an ultrasound probe: a study of their physical properties and stability. Powder Technol. 224, 138-146.

Mondragon, R., Segarra, C., Martinez-Cuenca, R., Julia, J.E., Jarque, J.C., 2013. Experimental characterization and modeling of thermophysical properties of nanofluids at high temperature conditions for heat transfer applications. Powder Technol. 249, 516-529.

Murshed, S.M.S., Leong, K.C., Yang, C., 2005. Enhanced thermal conductivity of $\mathrm{TiO}_{2}-$ water based nanofluids. Int. J. Therm. Sci. 44, 367-373.

Murshed, S.M.S., Leong, K.C., Yang, C., 2008. Investigations of thermal conductivity and viscosity of nanofluids. Int. J. Therm. Sci. 47, 560-568.

Nicolini, K.P., Fukamachi, C.R.B., Wypych, F., Mangrich, A.S., 2009. Dehydrated halloysite intercalated mechanochemically with urea: thermal behavior and structural aspects. J. Colloid Interf. Sci. 338, 474-479.

Özerinç, S., Kakac, S., Yazicioglu, A.G., 2010. Enhanced thermal conductivity of nanofluids: a state-of-the-art review. Microfluid. Nanofluid. 8, 145-170.

Pasbakhsh, P., Churchman, G.J., Keeling, J.L., 2013. Characterisation of properties of various halloysites relevant to their use as nanotubes and microfibre fillers. Appl. Clay Sci. 74, 47-57.

Pastoriza-Gallego, M. J., Casanova, C., Paramo, R., Barbes, B., Legido, J.L., Piñeiro, M.M., 2009 A study on stability and thermophysical properties (density and viscosity) of Al2O3 in water nanofluid. J. Appl. Phys. 106, 064301.

Pastoriza-Gallego, M.J., Lugo, L., Legido, J.L., Piñeiro, M.M., 2011. Themal conductivity and viscosity measurements of ethylene glycol-based $\mathrm{Al}_{2} \mathrm{O}_{3}$ nanofluids. Nanoscale Res. Lett. 6, 221.

Prasher, R., Phelan, P.E., Bhattacharya, P., 2006. Effect of aggregation kinetics on the thermal conductivity of nanoscale colloidal solutions (nanofluid). Nano Lett. 6, 1529-1534.

Putnam, S.A., Cahill, D.G., Braun, P.V., Ge, Z.B., Shimmin, R.G., 2006. Thermal conductivity of nanoparticle suspensions. J. Appl. Phys. 99, 084308
Quemada, D., 1977. Rheology of concentrated disperse systems and minimum energy dissipation principle. I. Viscosity-concentration relationship. Rheol. Acta 16, 82-94.

Rozynek, Z., Zacher, T., Janek, M., Čaplovičová, M., Fossum, J.O., 2013. Electric-field-induced structuring and rheological properties of kaolinite and halloysite. Appl. Clay Sci. 77-78, 1-9.

Saidur, R., Leong, K.Y., Mohammad, H.A., 2011. A review on applications and challenges of nanofluids. Renew. Sustain. Energy Rev. 15, 1646-1668.

Segarra, C., Jarque, J.C., Castello, J., Mondragon, R., Juliá, J.E., Hernández, L., MartínezCuenca, R., 2013. Characterization of Physical Properties of Nanofluids with Carbon Nanotubes for Heat Transfer Applications. 8th World Conference on Experimental Heat Transfer, Fluid Mechanics, and Thermodynamics, pp. 1-7.

Shima, P.D., Philip, J., Raj, B., 2010. Influence of aggregation on thermal conductivity in stable and unstable nanofluids. Appl. Phys. Lett. 97, 153113.

Talaei, Z., Reza, A., Rashidi, A., Amrollahi, A., Emami, M., 2011. The effect of functionalized group concentration on the stability and thermal conductivity of carbon nanotube fluid as heat transfer media. Int. Commun. Heat Mass Trans. 38, 513-517.

Tan, D.Y., et al., 2014. Loading and in vitro release of ibuprofen in tubular halloysite. Appl. Clay Sci. (In Press).

Venerus, D.C., et al., 2010. Viscosity measurements on colloidal dispersions (nanofluids) for heat transfer applications. Appl. Rheol. 20, 44582.

Vergaro, V., Abdullayev, E., Lvov, Y.M., Zeitoun, A., Cingolani, R., Rinaldi, R., Leporatti, S. 2010. Cytocompatibility and Uptake of Halloysite Clay Nanotubes. Biomacromolecules $11,820-826$

Warrier, P., Yuan, Y., Beck, M.P., Teja, A.S., 2010. Heat transfer in nanoparticle suspensions: modelling of thermal conductivity of nanofluids. AIChE J. 56, 3243-3256.

Wu, C., Cho, T.J., Xu, J., Lee, D., Yang, B., Zachariah, M.R., 2010. Effect of clustering on the effective thermal conductivity of concentrated silica colloids. Phys. Rev. E. 81, 011406

Xie, H.Q., Lee, H., Youn, W., Choi, M., 2003. Nanofluids containing multiwalled carbon nanotubes and their enhanced thermal conductivities. J. Appl. Phys. 94, 4967-4971.

Yu, W., Xie, H., Li, Y., Chen, L., Wang, Q., 2012. Experimental investigation on the heat transfer properties of $\mathrm{Al}_{2} \mathrm{O}_{3}$ nanofluids using the mixture of ethylene glycol and water as base fluid. Powder Technol. 230, 14-19.

Yuan, P., Tan, D., Annabi-Bergaya, F., Yan, W., Fan, M., Liu, D., He, H., 2012. Changes in structure, morphology, porosity, and surface activity of mesoporous halloysite nanotubes under heating. Clay Clay Miner. 60, 561-573.

Zhang, Y, Cao, H.M., Fei, W.W. Cui, D.X., Jia, N.Q, 2012. Direct electrochemistry and electrocatalysis of hemoglobin immobilized into halloysite nanotubes/room temperature ionic liquid composite film. Sensors Actuators B Chem. 162, 143-148. 